\title{
Interactions between ENSO, Transient Circulation, and Tropical Convection over the Pacific
}

\author{
AdRiAn J. MATTHEWS \\ Cooperative Institute for Research in Environmental Sciences, University of Colorado/NOAA, and \\ NOAA/Aeronomy Laboratory, Boulder, Colorado \\ GEORGE N. KILADIS \\ NOAA/Aeronomy Laboratory, Boulder, Colorado
}

(Manuscript received 28 July 1998, in final form 4 January 1999)

\begin{abstract}
The interannual variability of transient waves and convection over the central and eastern Pacific is examined using 30 northern winters of NCEP-NCAR reanalyses (1968/69-1997/98) and satellite outgoing longwave radiation data starting in 1974. There is a clear signal associated with the El Niño-Southern Oscillation, such that differences in the seasonal-mean basic state lead to statistically significant changes in the behavior of the transients and convection (with periods less than 30 days), which then feed back onto the basic state.

During a warm event (El Niño phase), the Northern Hemisphere subtropical jet is strengthened over the central Pacific; the region of upper-tropospheric mean easterlies over the tropical western Pacific expands eastward past the date line, and the upper-tropospheric mean "westerly duct" over the tropical eastern Pacific is weakened. The transients tend to propagate along the almost continuous waveguide of the subtropical jet; equatorward propagation into the westerly duct is reduced. The transient convective events over the ITCZ typically observed to be associated with these equatorward-propagating waves are subsequently reduced both in number and magnitude, leading to a seasonal-mean net negative diabatic heating anomaly over the central Pacific from $10^{\circ}$ to $20^{\circ} \mathrm{N}$, which then feeds back onto the basic state. During a cold event (La Niña phase), the situation is reversed. The different propagation characteristics of the transients in El Niño and La Niña basic states are well simulated in initial value experiments with a primitive equation model.
\end{abstract}

\section{Introduction}

In the last decade, several studies have linked transient deep convection over the central and eastern $\mathrm{Pa}$ cific intertropical convergence zone (ITCZ) with extratropical wave trains that propagate equatorward into the region of mean equatorial westerlies during northern winter and spring. A brief summary of these interactions is provided below; the reader is referred to Kiladis (1998) and references therein for a more complete description. Deep convection is enhanced in the region of ascent and reduced static stability in the poleward flow ahead of upper-level troughs (cyclonic anomalies) in the wave train. The mean period of these waves and their associated transient convection is around 12 days.

The propagation characteristics of the wave trains are governed to reasonable accuracy by barotropic Rossby

Corresponding author address: Dr. Adrian J. Matthews, School of Environmental Sciences, University of East Anglia, Norwich NR4 7TJ, United Kingdom.

E-mail: a.matthews@uea.ac.uk wave dynamics on a time-mean or "basic state" flow. Mean upper-tropospheric tropical easterlies prevent Rossby wave propagation into the deep Tropics, beyond a "critical line" where the zonal phase speed of the Rossby wave equals the basic-state zonal wind. However, the region of mean upper-tropospheric westerlies over the central and eastern equatorial Pacific in northern winter and spring (the "westerly duct") allows Rossby wave trains to propagate deep into the Tropics and to disperse across the equator (Webster and Holton 1982). A further result from barotropic Rossby wave theory is that the subtropical jets will act as waveguides, such that wave activity will tend to propagate preferentially along the jets (Hoskins and Ambrizzi 1993).

As Rossby waves are precluded from propagating into the region of mean upper-tropospheric tropical easterlies over the Eastern Hemisphere, the transient convection there is of a markedly different character to that in the upper-tropospheric tropical westerlies over the Western Hemisphere. In regions of mean upper-tropospheric easterlies, anomalous equatorial easterlies and meridional outflow around subtropical anticyclones are associated with submonthly transient convection (Kiladis 
and Weickmann 1992a). These circulations tend to peak following the maximum in the OLR signal, suggesting forcing of the circulation by the convection.

During northern summer, the westerly duct is replaced by upper-tropospheric easterlies across the entire Pacific basin, and Rossby waves cannot disperse through the Tropics. The relationship between transient convection and circulation over the eastern Pacific is then similar to that over the Eastern Hemisphere, as described above (Kiladis and Weickmann 1997).

The basic-state zonal wind over the Pacific changes on intraseasonal timescales, in particular with the Madden-Julian oscillation (MJO). Matthews and Kiladis (1999) studied the interaction between the MJO and the high-frequency transient waves and convection during northern winter. They found that during the phase of the MJO with enhanced convection over the east Indian Ocean and Indonesia and suppressed convection over the South Pacific convergence zone, both the AsianPacific jet and the region of upper-tropospheric tropical easterlies over the warm pool are displaced westward. These changes in the basic state lead to a weaker or "leakier" waveguide in the Asian-Pacific jet, with a westward-displaced "forbidden" region of tropical easterlies, such that high-frequency transients propagate equatorward into the deep Tropics over the central $\mathrm{Pa}$ cific near the date line. As these waves induce convection ahead of their upper-level cyclonic disturbances, there is an enhancement of high-frequency convective variability over the central Pacific ITCZ during this phase of the MJO. This enhanced convective variability appears to project back onto longer timescales and forms an integral part of the slowly varying diabatic heating field of the MJO. In the opposite phase of the MJO with enhanced convection near the date line, the Asian-Pacific jet is extended eastward and there is an almost continuous waveguide across the Pacific. Together with the expanded region of tropical easterlies over the warm pool, this leads to a more zonal propagation of highfrequency transients along the waveguide with less equatorward propagation and, hence, reduced high-frequency convective variability over the tropical central Pacific.

The basic state will also vary on interannual timescales, in particular with respect to El Niño-Southern Oscillation (ENSO). Although the timescale of ENSO is very different to that of the MJO, the spatial patterns of convection and atmospheric circulation anomalies are similar (Lau and Chan 1988). During a cold event, or La Niña phase of the ENSO cycle, the mean convection over the "warm pool" region of the Maritime Continent and western Pacific is amplified. The westerly duct over the equatorial eastern Pacific is strengthened, and it seems plausible that this would lead to enhanced equatorward propagation of transient waves and increased transient convection over the central Pacific ITCZ.

Conversely, during a warm event or El Niño phase of the ENSO cycle, the region of high sea surface tem- peratures (SSTs) of the western Pacific expands eastward beyond the date line, with deep convection also shifting eastward. This leads to a change in the seasonalmean atmospheric circulation pattern, with an expanded region of tropical easterlies over the central Pacific, and a weakened westerly duct. The Asian-Pacific jet also extends eastward into the central Pacific and anomalous downstream flow is established over the North Pacific and North America (e.g., Hoerling et al. 1997).

This study examines the link between the interannual and transient variability over the central and eastern Pacific. Section 2 describes the data used in the analysis. An index of the interannual variability of the basic-state flow is developed in section 3 and used to describe the interannual variability of transient circulation and convection (sections 4 and 5). The propagation characteristics of the transients and the feedback of the transient convection onto the mean flow are assessed further using a primitive equation model in section 6 , and a summary and discussion are presented in section 7 .

\section{Data}

Two primary datasets are used in this study: 200-mb winds from 30 northern winters (December-February, DJF, 1968/69-1997/98) were obtained from the National Centers for Environmental Prediction-National Center for Atmospheric Research (NCEP-NCAR) reanalysis dataset. The reanalysis uses the same, state-of-the-art, data assimilation scheme throughout the whole period and, therefore, provides a consistent dataset, free of the problems caused by changes in the operational analyses (Kalnay et al. 1996). An interpolated satellite OLR dataset (Liebmann and Smith 1996) is used as a proxy for deep tropical convection (Arkin and Ardanuy 1989) and was available for 22 northern winters (1974/75-1976/ 77 and 1979/80-1997/98). The winters of 1977/78 and 1978/79 were not available due to missing data from 17 March 1978 to 31 December 1978, and the data lost due to the weighting requirements of the Lanczos filter described below.

\section{Strong jet and weak jet basic states}

\section{a. Zonal wind index}

It is anticipated that changes in the transients will be directly related to changes in the basic-state circulation. Hence, for the purposes of this study a circulation index based on interannual zonal wind anomalies is used. The equatorward propagation of the transients and their association with transient convection over the ITCZ is strongest in the sector from $160^{\circ}$ to $130^{\circ} \mathrm{W}$; therefore, the interannual variability of the transients and convection is likely to be most sensitive to basic-state changes in this region. The actual dominant mode of interannual basic-state changes is also in this sector; during a warm event the positive SST anomalies and enhanced tropical 


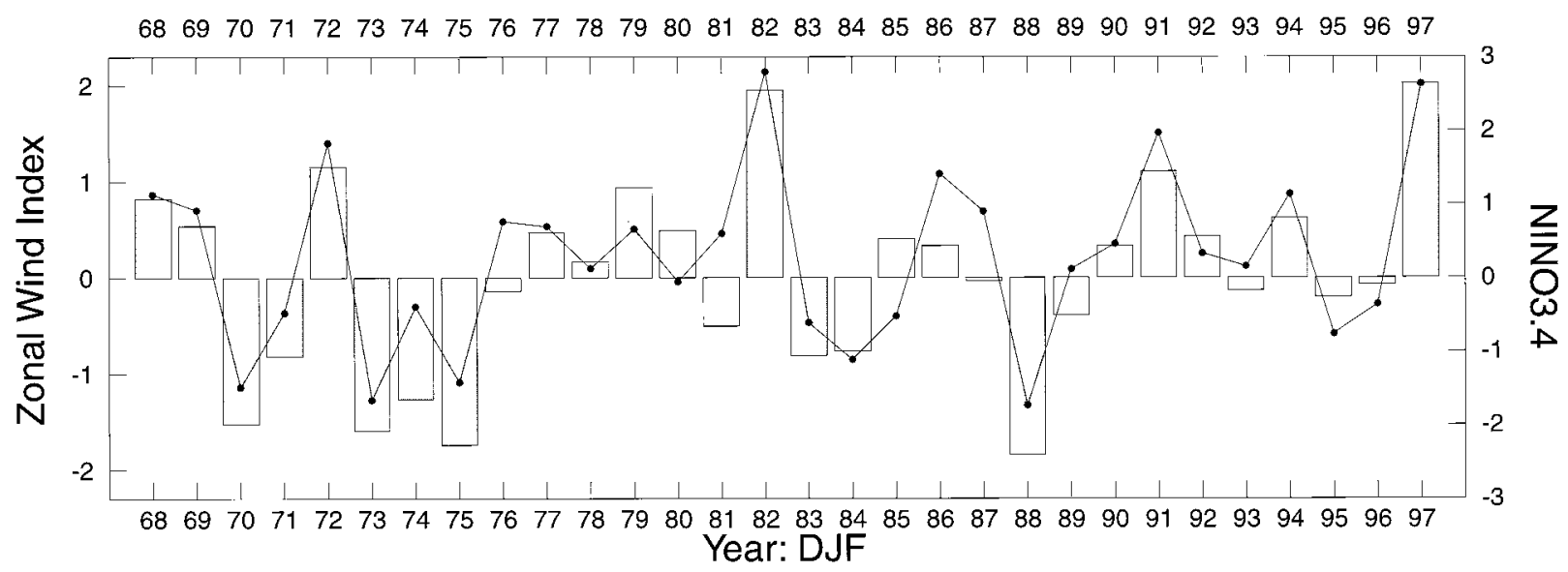

FIG. 1. Zonal wind index (ZWI) bar chart. Winters that make up the strong jet (SJ: highest seven values of the ZWI) and weak jet (WJ: lowest seven values of the ZWI) winter composites are shaded. The NINO3.4 SST index is indicated by the solid line. Dec-Jan-Feb (DJF) $1968 / 69$ is plotted as 68 .

convection over the central Pacific are associated (at least partly) with a modified equatorial Rossby wave response (Jin and Hoskins 1995) such that there is an anomalous upper-tropospheric anticyclone in the Northern Hemisphere with anomalous westerlies along $30^{\circ} \mathrm{N}$ extending the Asian-Pacific jet, and anomalous easterlies in the deep Tropics weakening the westerly duct (e.g., Kiladis and Mo 1998, their Fig. 6). A zonal wind index (ZWI) based on these anomalies is defined as the normalized difference between the seasonal-mean 200$\mathrm{mb}$ zonal wind averaged over $\left(15^{\circ}-30^{\circ} \mathrm{N}, 160^{\circ}-130^{\circ} \mathrm{W}\right)$ and $\left(0^{\circ}-15^{\circ} \mathrm{N}, 160^{\circ}-130^{\circ} \mathrm{W}\right)$. Figure 1 shows the ZWI for each northern winter from DJF 1968/69 to 1997/98 (it should be noted that results are relatively insensitive to the exact boundaries of these regions).

The NINO3.4 index is also shown for comparison in Fig. 1. This is the anomalous SST over the equatorial central Pacific, averaged over $5^{\circ} \mathrm{S}-5^{\circ} \mathrm{N}, 170^{\circ}-120^{\circ} \mathrm{W}$. The two indices are highly positively correlated with a correlation coefficient of $r=0.90$ (statistically significant at the $1 \%$ level), consistent with the model described above.

The 7 of the 30 northern winters with the highest values of the ZWI are defined as strong jet (SJ) winters, and the 7 lowest values of the ZWI correspond to weak jet (WJ) winters (shaded in Fig. 1; see Table 1). The El

TABLE 1. Strong jet and weak jet northern winters, as defined from the zonal wind index in Fig. 1. An asterisk indicates a winter for which OLR data are available.

\begin{tabular}{ll}
\hline \hline Strong jet & Weak jet \\
\hline $1968 / 69$ & $1970 / 71$ \\
$1972 / 73$ & $1971 / 72$ \\
$1979 / 80^{*}$ & $1973 / 74$ \\
$1982 / 83^{*}$ & $1974 / 75^{*}$ \\
$1991 / 92^{*}$ & $1975 / 76^{*}$ \\
$1994 / 95^{*}$ & $1983 / 84^{*}$ \\
$1997 / 98^{*}$ & $1988 / 89^{*}$ \\
\hline
\end{tabular}

Niño or warm event years of 1968/69, 1972/73, 1982/ 83, 1991/92, 1994/95, and 1997/98 are selected as SJ events, and the La Niña or cold event years of 1970/ $71,1973 / 74,1975 / 76$, and 1988/89 are selected as WJ events, in close agreement with the NINO3.4 index.

Although the upper-tropospheric circulation over the central Pacific is strongly tied to the ENSO cycle, it also exhibits other interannual variability that is not related to ENSO. As this study is concerned with the interannual variability of the transients over the central and eastern Pacific, which is directly linked to anomalies in the atmospheric basic state, the ZWI is preferable to a more indirectly linked index, such as one based on SST.

\section{b. Composite mean zonal wind fields}

The composite-mean 200-mb zonal wind field from the seven SJ winters is shown in Fig. 2a. The Northern Hemisphere subtropical jet is almost continuous across the domain, with westerlies exceeding $30 \mathrm{~m} \mathrm{~s}^{-1}$ from eastern Asia across the Pacific to North America. The region of 200-mb tropical easterlies over the western Pacific extends as far eastward as $155^{\circ} \mathrm{W}$, and the westerly duct is rather weak with only a small region of westerlies above $15 \mathrm{~m} \mathrm{~s}^{-1}$, near $110^{\circ} \mathrm{W}$.

The corresponding composite-mean field for the seven WJ winters is shown in Fig. 2b. There is now a distinct break in the Northern Hemisphere subtropical jet over the central Pacific, with westerlies less than 20 $\mathrm{m} \mathrm{s}^{-1}$ between $150^{\circ}$ and $120^{\circ} \mathrm{W}$ along $30^{\circ} \mathrm{N}$. The region of 200-mb tropical easterlies over the western Pacific has retracted westward to the date line and the westerly duct in the tropical eastern Pacific is very strong, with peak values on the equator over $25 \mathrm{~m} \mathrm{~s}^{-1}$.

The SJ minus WJ difference field in Fig. 2c emphasizes these anomalies. Over the central Pacific, the tropical easterly anomalies and subtropical westerly anom- 


\section{0-mb U}

\section{(a) Strong Jet Winter}

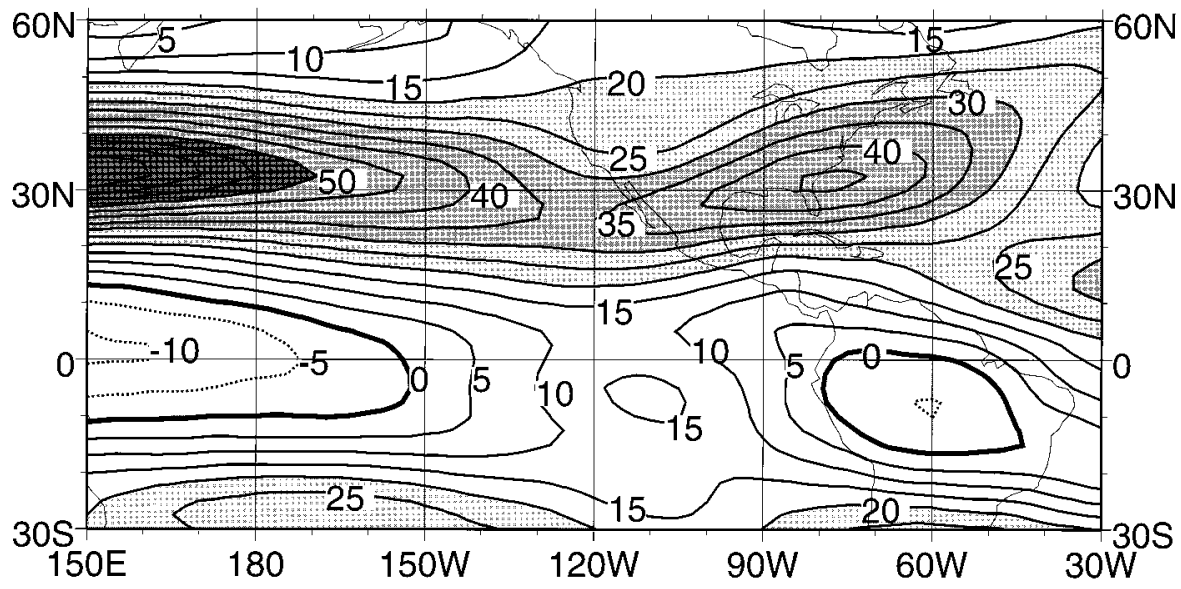

(b) Weak Jet Winter

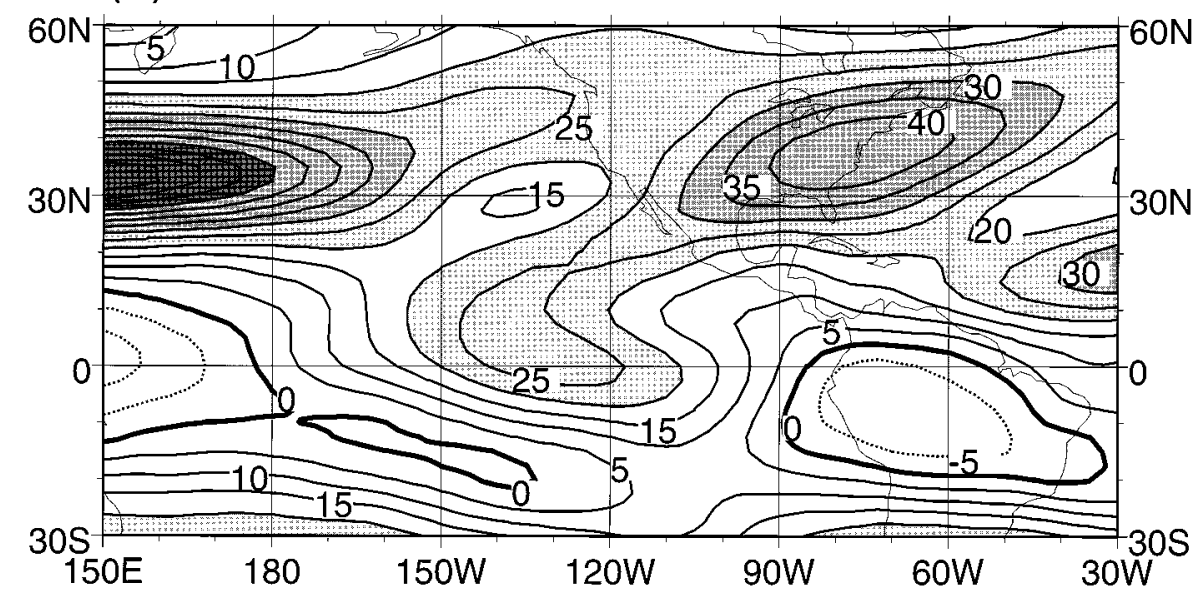

(c) Strong Jet - Weak Jet

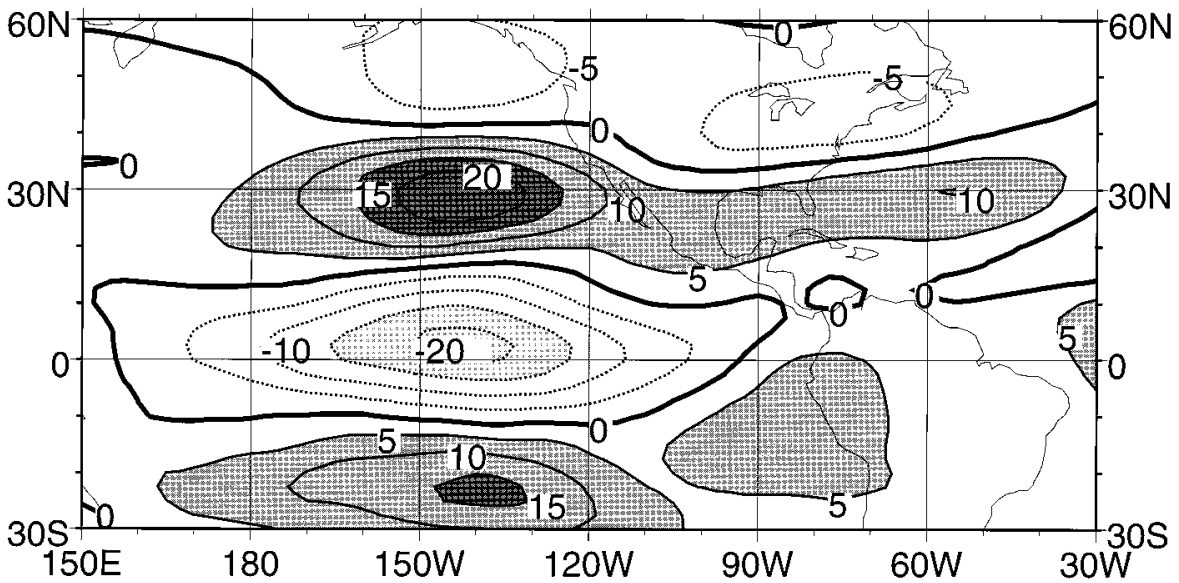

FIG. 2. The 200-mb zonal wind composite mean: (a) SJ winter, (b) WJ winter. Contour interval is 5 $\mathrm{m} \mathrm{s}^{-1}$; positive (negative) contours are solid (dashed), and the zero contour is thickened; easterlies are shaded lightly, and westerlies above 20,30 , and $50 \mathrm{~m} \mathrm{~s}^{-1}$ are shaded with increasing intensity. (c) Difference field (SJ - WJ). Contours as above, and easterly (westerly) anomalies in excess of $5 \mathrm{~m} \mathrm{~s}^{-1}$ are shaded lightly (darkly). 
alies in both hemispheres form part of the anomalous upper-tropospheric anticyclone pair associated with the anomalous deep convective heating over the central $\mathrm{Pa}$ cific during a warm event. In the Northern Hemisphere extratropics, the easterly anomalies south of Alaska and over central North America, and the westerly anomalies over the Gulf of Mexico and the Atlantic form part of the typical teleconnection pattern that is observed to occur during warm events (e.g., Rasmusson 1985; Hoerling et al. 1997). The statistical significance of the SJ minus WJ difference field for 200-mb zonal wind and other variables is discussed in the appendix.

\section{c. Composite mean tropical convection fields}

For further confirmation that the ZWI is primarily influenced by ENSO, Fig. 3 shows the composite mean OLR fields for (a) an SJ winter, (b) a WJ winter, and (c) the SJ minus WJ difference field. Note that the OLR data are only available for the last five SJ and four WJ winters (Table 1). During an SJ winter, deep tropical convection (indicated by low OLR values) is reduced over the Maritime Continent and enhanced over the equatorial central Pacific east of the date line. The ITCZ and SPCZ are shifted equatorward and eastward from their climatological positions during warm events, and vice versa during cold events, consistent with many previous ENSO studies (e.g., Kiladis and van Loon 1988; Hoerling et al. 1997).

The anomalies over the Pacific in Fig. $3 \mathrm{c}$ are commonly assumed to arise due to the displacement of the convergence zones, although the SST anomalies in these regions are typically very weak at this phase of ENSO (e.g., Kiladis and Diaz 1989). This points to more than just local forcing by SST in controlling the positioning of the convergence zones. In particular, to the north of the negative equatorial OLR anomaly over the central Pacific, there is a positive OLR anomaly between $10^{\circ}$ $25^{\circ} \mathrm{N}$ and $160^{\circ}-120^{\circ} \mathrm{W}$, signifying reduced (enhanced) mean convection in this region during an SJ (WJ) winter. It is argued below that this anomaly in the seasonalmean convection is due to changes in the transient waves and convection over the ENSO cycle.

\section{Interannual variability of transients}

\section{a. Diagnostics}

High-frequency transients over the central and eastern Pacific have been shown to have a mean period of 12 days and behave qualitatively like nondivergent barotropic Rossby waves (Kiladis 1998). Their behavior during different phases of the MJO has been interpreted in terms of Rossby wave dynamics by Matthews and Kiladis (1999).

The propagation of nondivergent barotropic Rossby waves on a longitudinally varying flow is described in detail in Hoskins and Ambrizzi (1993). A useful diag- nostic to describe the basic state is the total stationary wavenumber $K_{s}$, calculated from the time-mean zonal wind $\bar{U}$ :

$$
K_{s}=\left(\frac{\beta-\bar{U}_{y y}}{\bar{U}}\right)^{1 / 2},
$$

where $\beta$ is the meridional planetary vorticity gradient and $-U_{y y}$ is the meridional relative vorticity gradient (the contribution from the meridional wind has been neglected), and an overbar denotes time averaging. In addition, $K_{s}$ acts as a refractive index for stationary Rossby waves, such that waves are refracted toward (away from) regions of high (low) $K_{s}$. A modification can be made to account for nonstationary waves (Yang and Hoskins 1996); for the phase speeds of approximately $5 \mathrm{~m} \mathrm{~s}^{-1}$ that are relevant to the transients discussed here, the total wavenumber field is very similar.

The actual propagation characteristics of the highfrequency transients themselves can be described by the E-vector (Hoskins et al. 1983) in the form used by Hendon (1986):

$$
\mathbf{E}=\left(\frac{1}{2} \overline{v^{\prime 2}-u^{\prime 2}}-\overline{u^{\prime} v^{\prime}}\right),
$$

where a prime denotes a deviation from the time mean. These $u^{\prime}$ and $v^{\prime}$ perturbations are calculated by passing the daily data through a 121-weight high-pass Lanczos filter with a cutoff at 30 days. The E-vector is parallel to the group velocity (relative to the mean flow) of barotropic Rossby waves with the same zonal and meridional scales as the observed transients. The overall wave activity is measured by the perturbation kinetic energy, PKE:

$$
\mathrm{PKE}=\frac{1}{2}\left(\overline{u^{\prime 2}+v^{\prime 2}}\right)
$$

\section{b. Transient wave activity}

The 200-mb total stationary wavenumber $\left(K_{s}\right)$ field for a composite mean SJ basic state, together with the PKE and E-vector fields of the high-frequency transients, are shown in Fig. 4a. The interpretation of $K_{s}$ as a refractive index can be seen to be qualitatively valid. On the largest scales, $K_{s} \approx 4$ along $40^{\circ} \mathrm{N}$ and increases equatorward. Hence Rossby waves will tend to be refracted equatorward; this is consistent with the generally equatorward-pointing E-vectors along this latitude. The regions of tropical mean easterlies over the western $\mathrm{Pa}-$ cific and South America correspond to regions of imaginary $K_{s}$. As these regions are approached, $K_{s}$ increases up to the critical line, and the transients are refracted toward the tropical mean easterlies. However, once inside these regions, Rossby waves are evanescent, consistent with the very small E-vector amplitudes, and low values of PKE (not shown). The subtropical jet near $30^{\circ} \mathrm{N}$ corresponds to a local maximum of $K_{s} \approx 6$, flanked 
(a) Strong Jet Winter

\section{OLR}

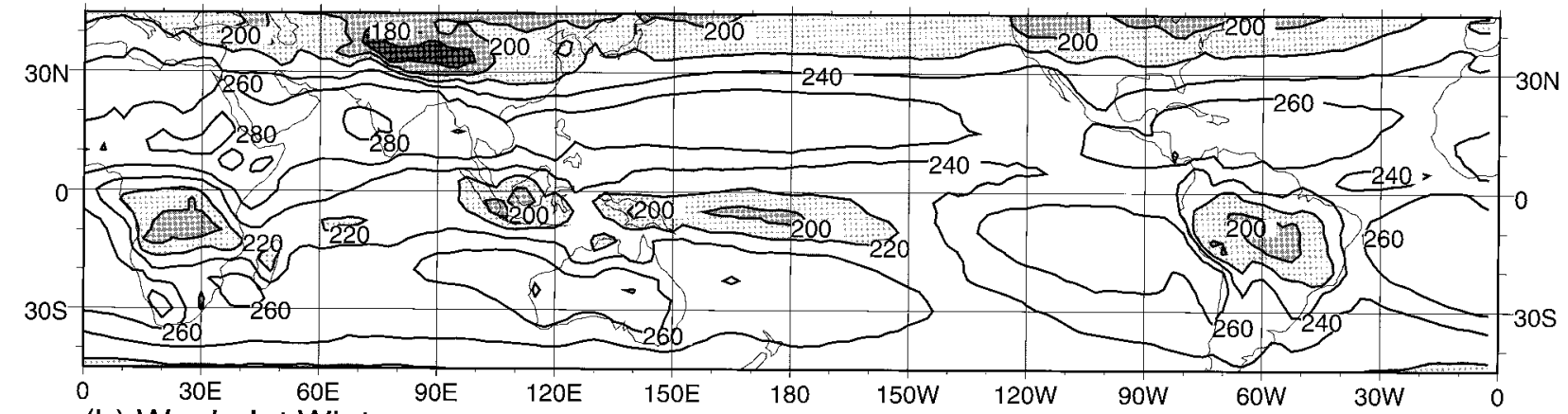

(b) Weak Jet Winter

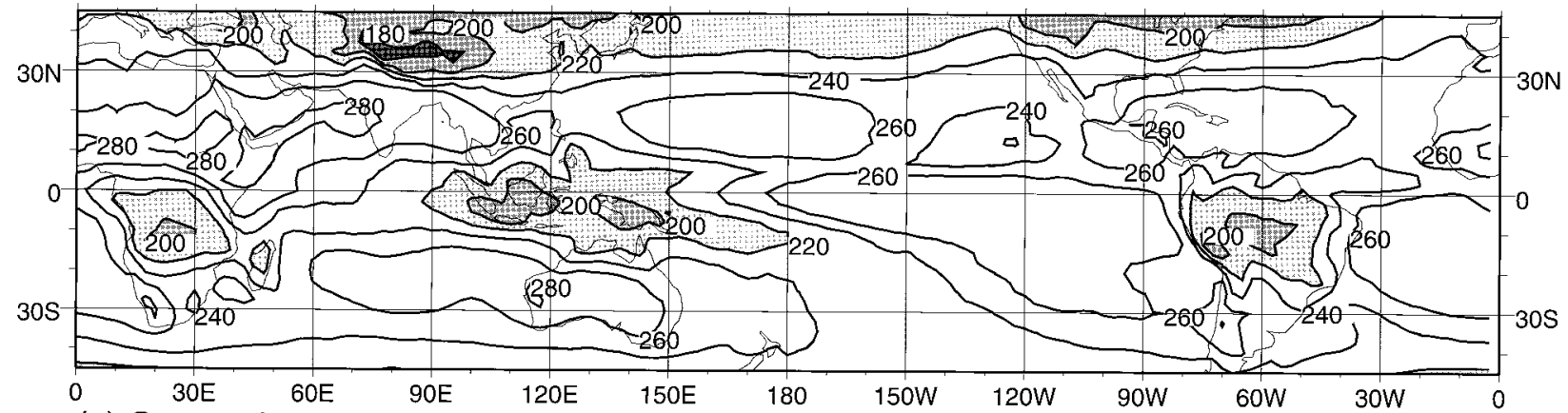

(c) Strong Jet - Weak Jet

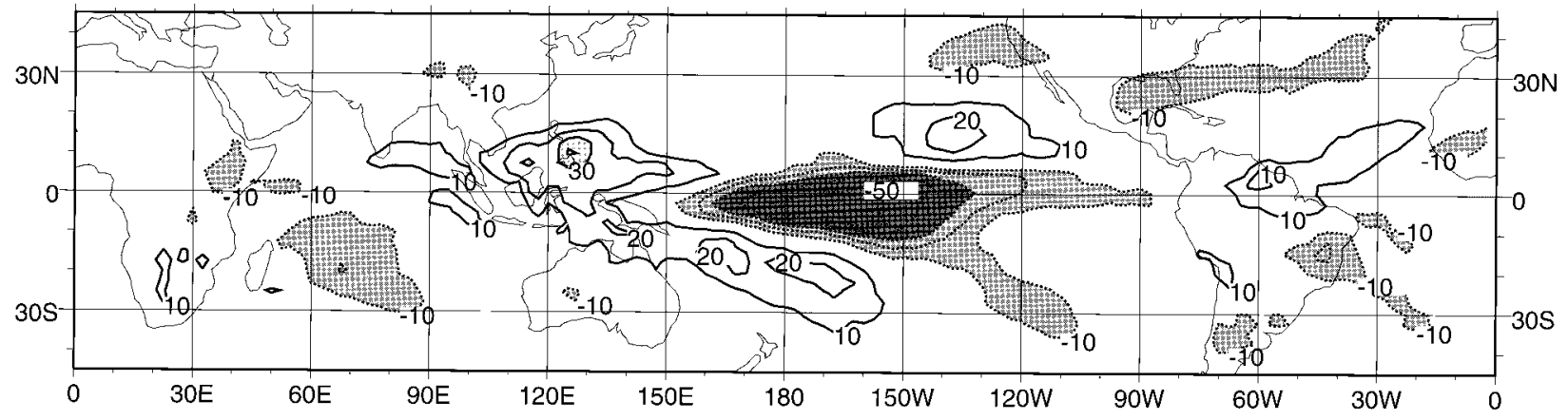

FIG. 3. OLR composite mean: (a) SJ winter, (b) WJ winter. Contour interval is $20 \mathrm{~W} \mathrm{~m}^{-2}$, with shading below $240 \mathrm{~W} \mathrm{~m}^{-2}$. (c) Difference field (SJ - WJ). Contour interval is $10 \mathrm{~W} \mathrm{~m}^{-2}$; positive (negative) contours are solid (dashed), the zero contour is omitted, and positive (negative) anomalies in excess of $10 \mathrm{~W} \mathrm{~m}^{-2}$ are shaded lightly (darkly).

on either side by local minima, and acts as a "waveguide" (Hoskins and Ambrizzi 1993). The jet, or waveguide, corresponds approximately to the region of maximum PKE, shown by the heavy contour at $250 \mathrm{~m}^{2} \mathrm{~s}^{-2}$. The westerly duct over the equatorial eastern Pacific precludes the existence of a critical line and allows waves to propagate into the deep Tropics.

However, the situation is not as straightforward as might first appear. The zonal wind on the equator is a local maximum of over $15 \mathrm{~m} \mathrm{~s}^{-1}$ at $110^{\circ} \mathrm{W}$, with regions of weaker westerlies below $15 \mathrm{~m} \mathrm{~s}^{-1}$ immediately to the north and south (Fig. 2a). Together with the proximity of the subtropical jet, this leads to a local weakening of the meridional vorticity gradient and a local minimum in $K_{s}$, especially to the north at $8^{\circ} \mathrm{N}, 110^{\circ} \mathrm{W}$ (Fig. $4 \mathrm{a}$ ). This local minimum in $K_{s}$ then refracts waves away from the region. This leads to the result that the strongest propagation of waves into the deep Tropics is actually to the west of the strongest equatorial westerlies, from $140^{\circ}$ to $130^{\circ} \mathrm{W}$. In the core of the westerly duct itself, there is only limited equatorward propagation.

The corresponding diagram for the composite mean WJ basic state is shown in Fig. 4b. The overall $\mathrm{K}_{\mathrm{s}}$ pattern is similar to that for the SJ winter, but there are some marked differences. The region of tropical mean easterlies and imaginary $K_{s}$ over the equatorial Pacific has retracted to the west of the date line, and Rossby waves may now propagate into the equatorial westerlies that 
(a) Strong Jet Winter: 200-mb Ks, <30-day E-vector

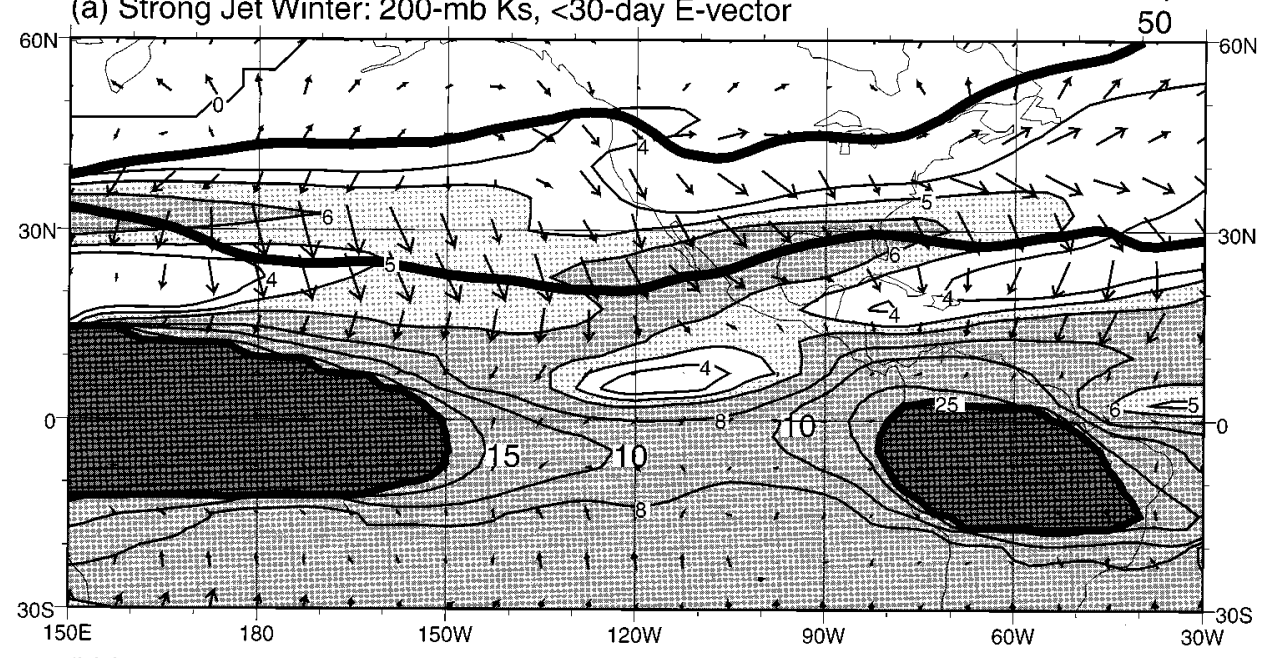

(b) Weak Jet Winter: 200-mb Ks, <30-day E-vector

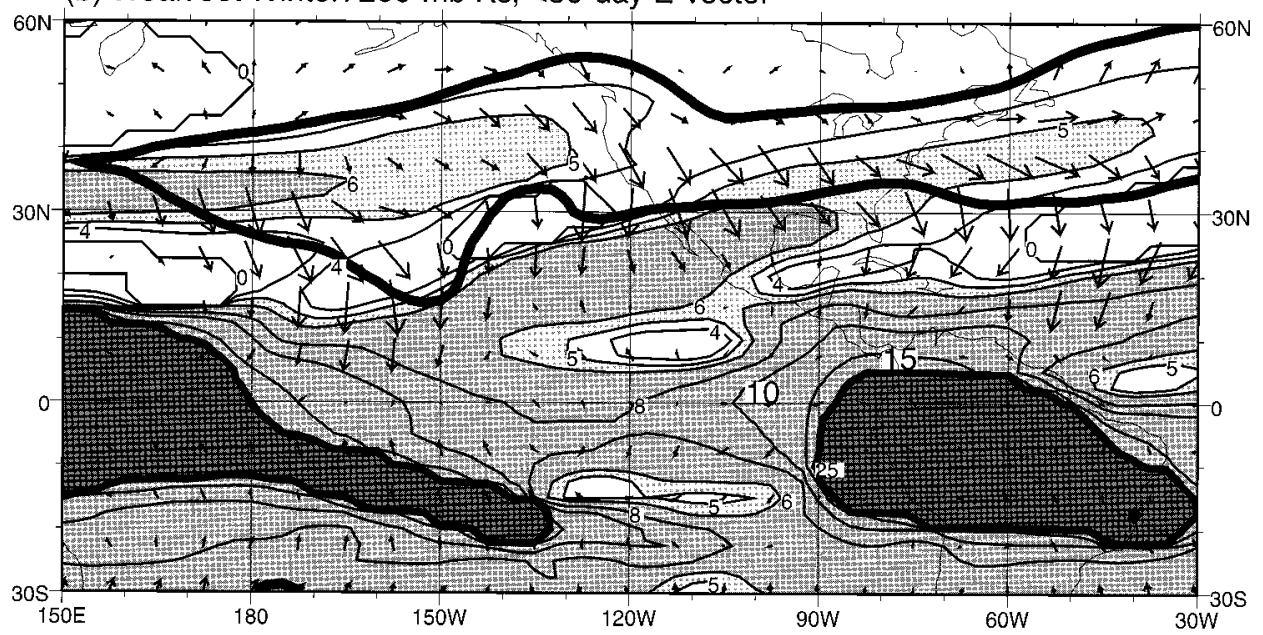

(c) Strong Jet - Weak Jet: 200-mb <30-day PKE, E-vector

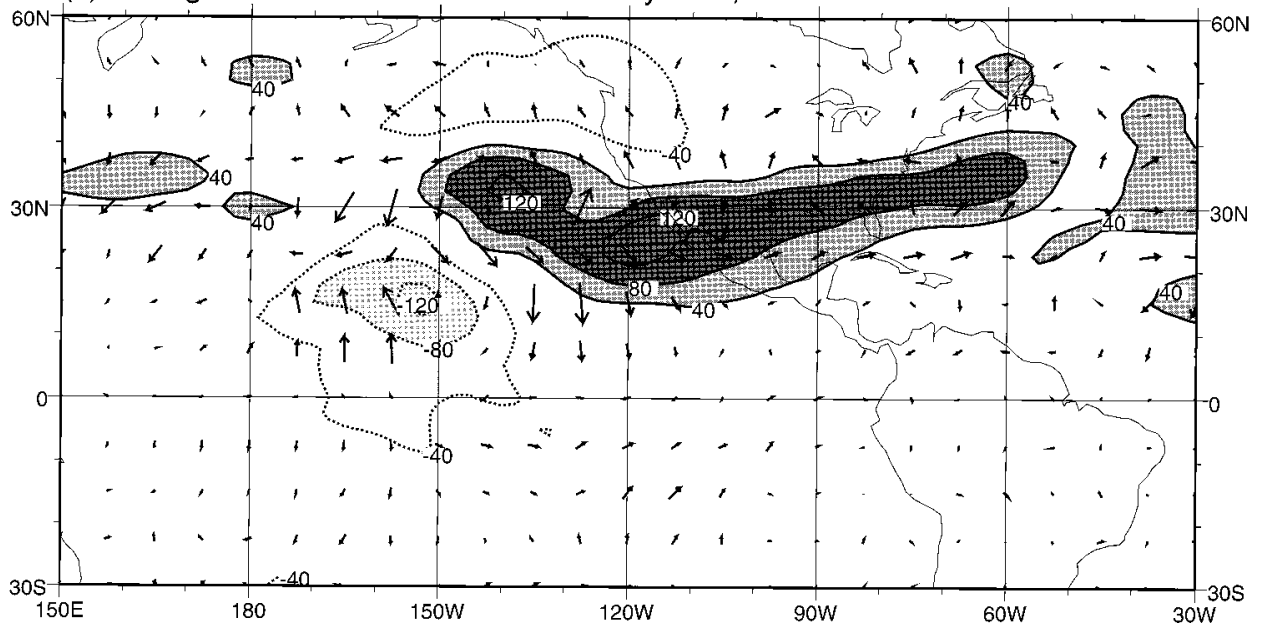

FIG. 4. (a) The 200-mb total stationary wavenumber $K_{s}$ and high-frequency $(<30$ day) PKE and E-vectors: SJ winter composite mean. Contours of $K_{s}$ are at zonal wavenumbers $0,4,5,6,8$, with a thickened contour at 25 to represent the transition to regions of easterly zonal wind and imaginary $K_{s}$; regions of negative absolute vorticity gradient are shaded lightly; regions between zonal wavenumber 5-6, 6-25, and regions of easterly zonal wind are shaded with increasing darkness. PKE is shown by a single heavy contour at $250 \mathrm{~m}^{2} \mathrm{~s}^{-2}$. E-vectors are plotted every $7.5^{\circ}$ for clarity, and reference E-vector is $50 \mathrm{~m}^{2} \mathrm{~s}^{-2}$. (b) As in (a) but for WJ winter. (c) Difference fields (SJ minus WJ); high-frequency PKE and E-vectors. Contour interval for PKE anomalies is $40 \mathrm{~m}^{2} \mathrm{~s}^{-2}$; positive (negative) contours are solid (dashed), the zero contour is omitted, and positive (negative) anomalies in excess of $40 \mathrm{~m}^{2} \mathrm{~s}^{-2}$ are shaded darkly (lightly). 
lie just east of the date line. The discontinuity in the Northern Hemisphere subtropical jet over the central Pacific leads to a weakening and even a reversal of the meridional vorticity gradient at $30^{\circ} \mathrm{N}, 135^{\circ} \mathrm{W}$. This produces a minimum in $K_{s}$, and Rossby waves will be refracted away from this region, as confirmed by the E-vector field.

This combination of features in the basic state during a WJ winter leads to enhanced equatorward propagation of the transients just east of the date line. This can be seen in the anomalously strong equatorward-pointing E-vectors near $15^{\circ} \mathrm{N}, 155^{\circ} \mathrm{W}$ in Fig. $4 \mathrm{~b}$, and as the northward-pointing E-vector anomalies in the SJ minus WJ difference field of Fig. 4c. A consistent signal is present in the PKE field; the region of maximum PKE extends southward into the Tropics at $150^{\circ} \mathrm{W}$ in Fig. $4 \mathrm{~b}$.

As the discontinuity in the subtropical jet during a WJ winter refracts Rossby waves away from this region, there is also a reduction in equatorward-propagating waves to the south and east, as shown by the very weak E-vectors around $15^{\circ} \mathrm{N}, 120^{\circ} \mathrm{W}$ in Fig. $4 \mathrm{~b}$. During an SJ winter there is no such obstacle to the waves and there is equatorward propagation right across the central Pacific (southward-pointing E-vectors along $15^{\circ} \mathrm{N}$ in Fig. 4a). This is clearly shown by the southward-pointing E-vector anomalies near $15^{\circ} \mathrm{N}, 120^{\circ} \mathrm{W}$ in Fig. $4 \mathrm{c}$.

The difference in high-frequency PKE between an SJ and a WJ winter is also shown in Fig. 4c. The band of positive PKE anomalies along $30^{\circ} \mathrm{N}$ over the eastern Pacific, North America, and the western Atlantic, together with the negative PKE anomalies to the north, are consistent with the almost continuous Pacific-North American jet during an SJ winter (Fig. 2a), as this stronger waveguide (Fig. 4a) will constrain the transients more tightly to the jet core. The negative PKE anomalies over the tropical central Pacific are coincident with the region of northward-pointing E-vector anomalies, and are consistent with the reduction (enhancement) in equatorward-propagating waves during an SJ (WJ) winter.

\section{c. Transient convective activity}

As a portion of transient convection on the $<30$ day timescale in the eastern Pacific ITCZ appears to be forced by equatorward-propagating waves, changes in this wave activity over the ENSO cycle may be expected to lead to changes in the transient convection. A convenient measure of the transient convection is the variance of the 30-day high-pass filtered OLR. The highfrequency OLR variance field for a composite-mean SJ winter is shown in Fig. 5a. Comparison with the mean OLR field for an SJ winter in Fig. 3a shows that regions of large high-frequency OLR variance tend to be in regions of low mean OLR. This is not surprising, as mean convection (low mean OLR) is made up of many individual convective events, which will be manifested as a large OLR variance. Hence the pattern of mean convection can be interpreted as an "envelope" of convective variability.

In particular, there is a band of enhanced high-frequency OLR variance along $5^{\circ} \mathrm{N}$ during an SJ winter (Fig. 5a), indicative of the large high-frequency convective activity along the equatorward-displaced ITCZ (Fig. 3a). During a WJ winter the high-frequency OLR variance along $5^{\circ} \mathrm{N}$ is relatively low, coincident with a weakened mean ITCZ, but it is enhanced to the north (Fig. 5b). These features can be clearly seen in the SJ minus WJ difference field (Fig. 5c). The negative anomaly centered at $15^{\circ} \mathrm{N}, 135^{\circ} \mathrm{W}$ shows that there is reduced transient convection during an SJ winter and enhanced transient convection during a WJ winter in this region. This is consistent with the reduction (enhancement) of equatorward-propagating transients over the central $\mathrm{Pa}-$ cific during an $\mathrm{SJ}(\mathrm{WJ})$ winter, described in the previous section. The features in Fig. 5c are very similar to those in a 6-25-day bandpass-filtered OLR variance anomaly field based upon the Southern Oscillation index (Vincent et al. 1998), confirming the close link between the ZWI and ENSO.

The strengthened storm track over North America and the western Atlantic along $30^{\circ} \mathrm{N}$ during an SJ winter can be seen as a band of enhanced high-frequency OLR variance in Fig. 5a (a positive anomaly in Fig. 5c). This is consistent with the positive kinetic energy anomalies over the region in the SJ minus WJ difference field of Fig. 4c. These positive OLR variance anomalies are too far from the equator to be a proxy for enhanced deep convective activity. However, they still likely represent increased transient cloudiness in the enhanced storm track.

Other features of note include the eastward shift of the envelope of transient convection within the SPCZ, and the region of enhanced transient convection in the southern Indian Ocean coincident with increases in mean convection over the areas (negative OLR anomalies in Fig. 3c).

Returning to the region over the Northern Hemisphere tropical Pacific described above, the reduction in the transient convective activity between SJ and WJ winters appears to lead to a reduction in the time-mean convection, as shown by the positive OLR anomaly centered near $15^{\circ} \mathrm{N}, 135^{\circ} \mathrm{W}$ in Fig. 3c. This hypothesis is investigated further by consideration of the unfiltered daily OLR time series averaged over a $10^{\circ} \times 10^{\circ}$ box from $10^{\circ}-20^{\circ} \mathrm{N}$ to $140^{\circ}-130^{\circ} \mathrm{W}$ in Fig. 6 . The five panels on the left show the OLR time series from the five SJ winters for which OLR data were available. There are many periods where the OLR is approximately constant at a value near $275 \mathrm{~W} \mathrm{~m}^{-2}$, for example, the latter half of February 1980 in Fig. 6a. These correspond to periods of clear skies when the OLR that is emitted by a cloudfree atmosphere and represent the maximum OLR value attainable. Periods when high cloud tops and deep convection are present are indicated by negative OLR perturbations from this clear-sky "reference level" at 275 
(a) Strong Jet Winter

\section{$<30$-day OLR Variance}

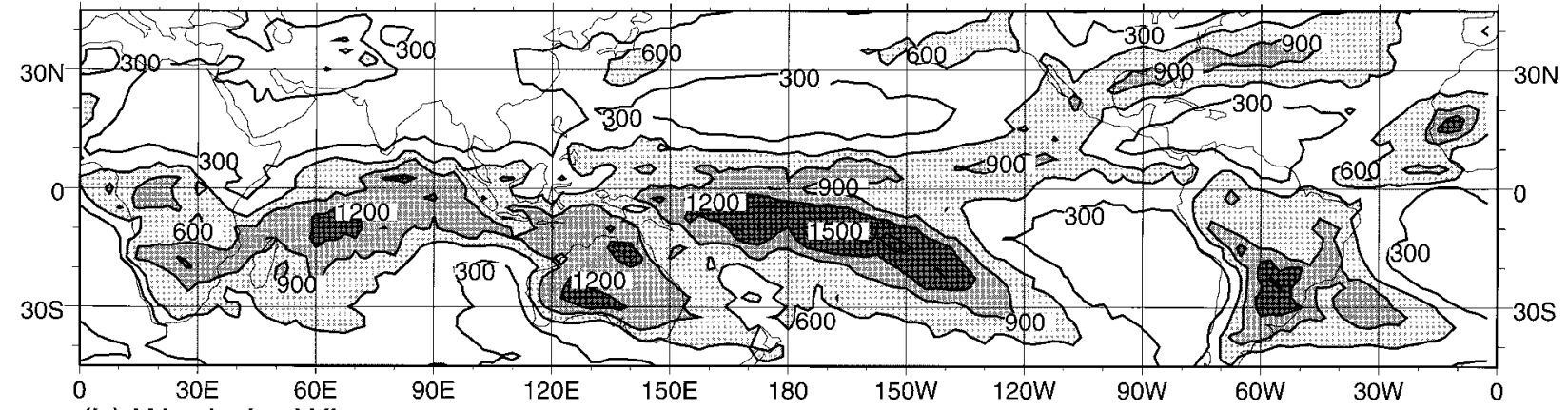

(b) Weak Jet Winter

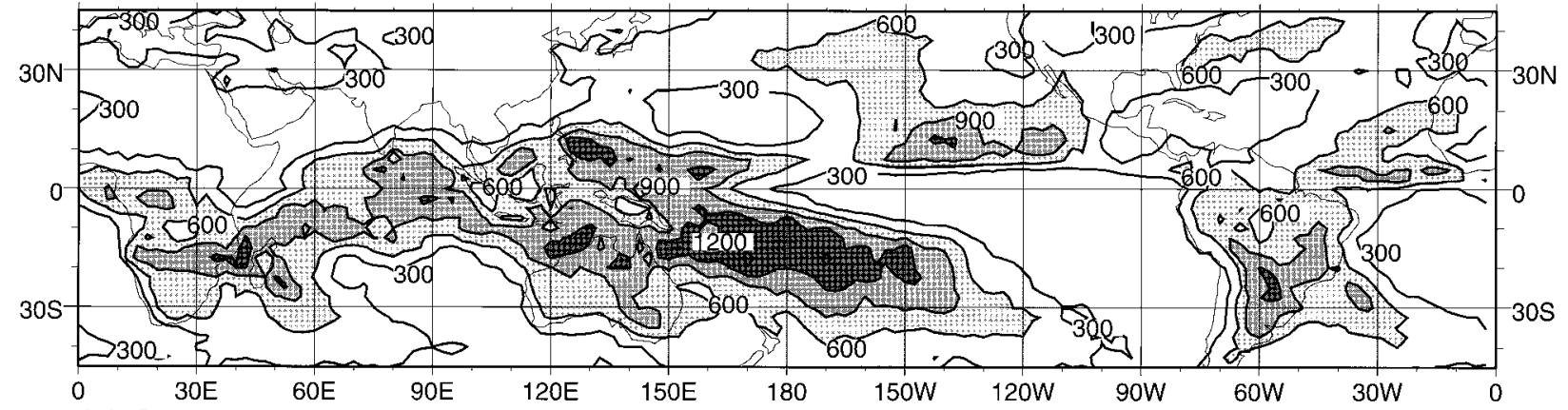

(c) Strong Jet - Weak Jet

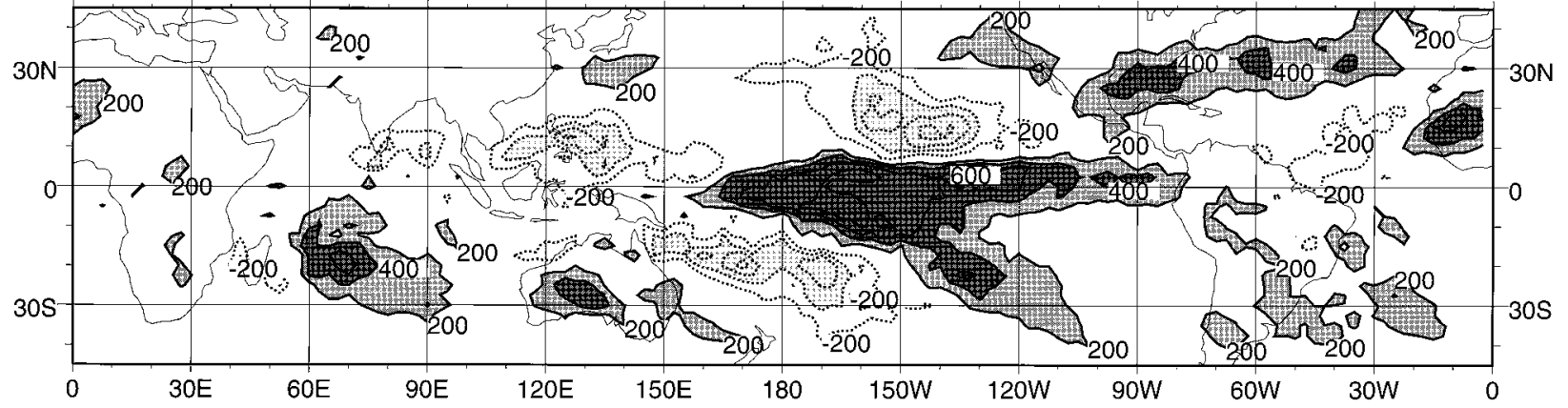

FIG. 5. High-frequency OLR variance ( $<30$ days) composite mean: (a) SJ winter, (b) WJ winter. Contour interval is $300 \mathrm{~W}^{2} \mathrm{~m}^{-4}$. (c) Difference field (SJ - WJ). Contour interval is $200 \mathrm{~W}^{2} \mathrm{~m}^{-4}$; positive (negative) contours are solid (dashed), the zero contour is omitted, and positive (negative) anomalies in excess of $200 \mathrm{~W}^{2} \mathrm{~m}^{-4}$ are shaded darkly (lightly).

$\mathrm{W} \mathrm{m}^{-2}$. During the five SJ winters (Figs. 6a-e) there are relatively few large negative OLR perturbations, or periods of transient convective activity. This is quantified by a variance of only $351 \mathrm{~W}^{2} \mathrm{~m}^{-4}$ and a mean of $257 \mathrm{~W} \mathrm{~m}^{-2}$, which is only $18 \mathrm{~W} \mathrm{~m}^{-2}$ less than the clearsky reference level.

In contrast, the four WJ winters in Figs. $6 \mathrm{f}-\mathrm{i}$ show more frequent and larger negative OLR perturbations. This increase in transient convective activity is reflected in an almost doubled variance of $682 \mathrm{~W}^{2} \mathrm{~m}^{-4}$, which drives the mean down to $237 \mathrm{~W} \mathrm{~m}^{-2}$, a decrease of 38 $\mathrm{W} \mathrm{m^{-2 }}$ from the clear-sky reference value. Alternatively, if the increase in mean convection during a WJ winter was caused by an increase in discrete convective events (measured by negative-definite departures from a ref- erence level of $275 \mathrm{~W} \mathrm{~m}^{-2}$ ), then the OLR distribution would be expected to be asymmetric and negatively skewed toward the lower OLR values associated with these discrete events.

All five OLR time series from the SJ winters have a negative sample skewness coefficient (shown in the lower right of the panels in Fig. 6) that is statistically significantly different from zero at the $0.5 \%$ level. Details of the significance testing are given in the appendix. The OLR time series for the first WJ winter (DJF 1974/ 75) does not have significant negative skewness and can be regarded as describing perturbations about a mean state of active convection. Visual inspection of Fig. $6 f$ confirms this. However, the remaining three WJ winters do have significantly negative skewness at the $1 \%, 5 \%$, 
Strong Jet Winters

(a) $1979 / 80$

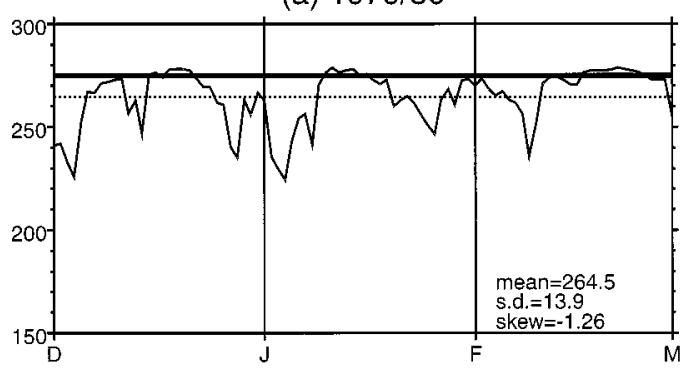

(b) $1982 / 83$

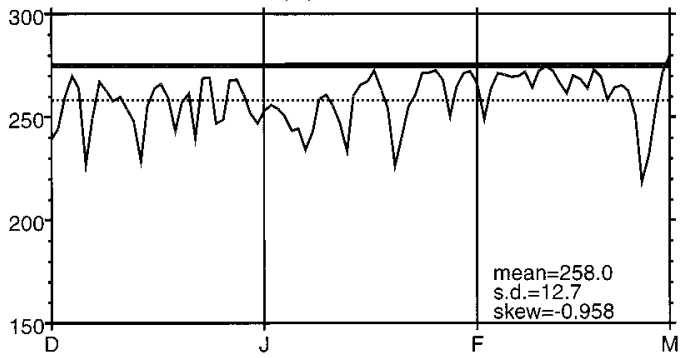

(c) $1991 / 92$

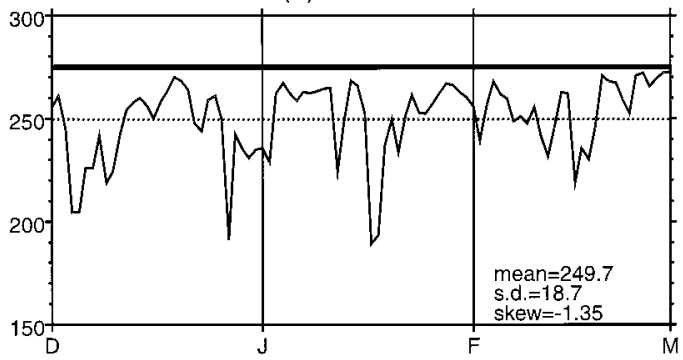

(d) $1994 / 95$

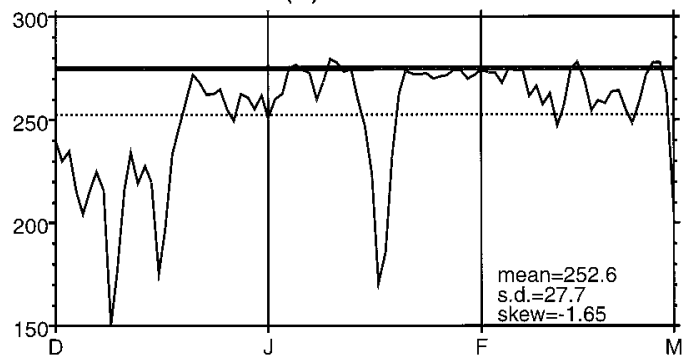

(e) $1997 / 98$

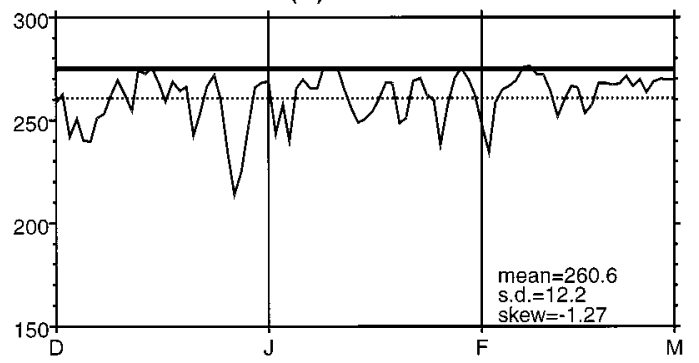

Weak Jet Winters

(f) $1974 / 75$

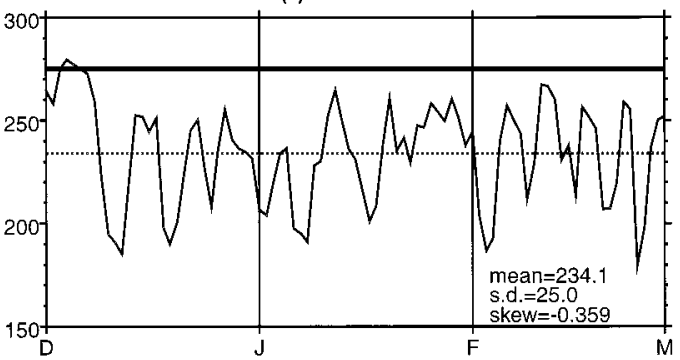

(g) $1975 / 76$

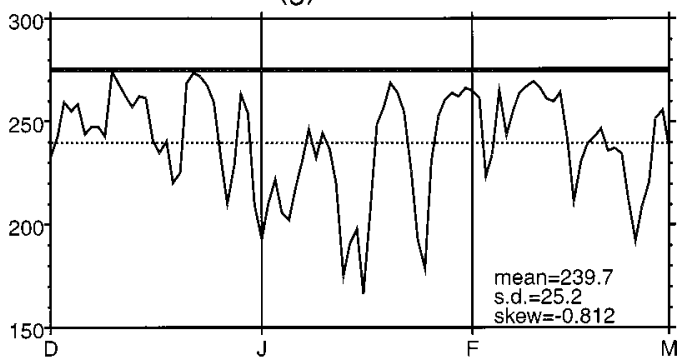

(h) $1983 / 84$

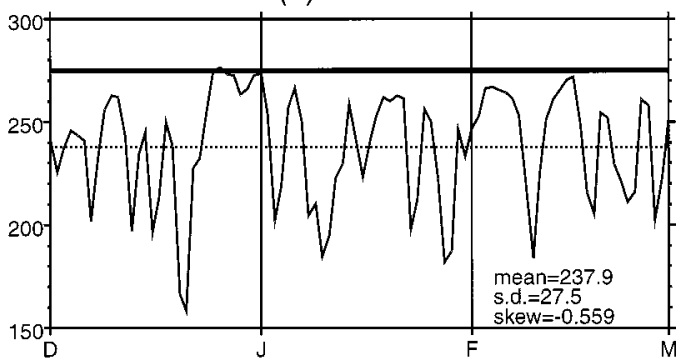

(i) $1988 / 89$

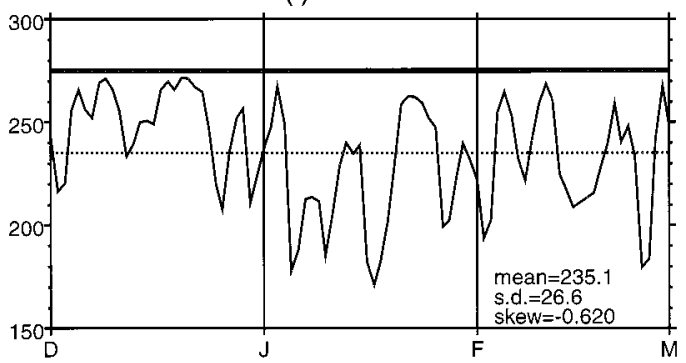

FIG. 6. Raw daily OLR time series (in $\mathrm{W} \mathrm{m} \mathrm{m}^{-2}$ ), averaged over the $10^{\circ} \times 10^{\circ}$ box from $10^{\circ} \mathrm{N}-20^{\circ} \mathrm{N}, 140^{\circ}-130^{\circ} \mathrm{W}$, for the five strong jet winters (a) 1979/80, (b) 1982/83, (c) 1991/92, (d) 1994/95, (e) 1997/98 and the four weak jet winters (f) 1974/75, (g) 1975/76, (h) 1983/ 84 , (i) $1988 / 89$ for which OLR data were available. The first days of the month are shown on the horizontal axis. A thick line is shown at $275 \mathrm{~W} \mathrm{~m}^{-2}$ to represent the clear-sky value. The mean value for each season is shown by the dotted line, and together with the standard deviation and skewness in the lower-right corner of each panel. 
and 5\% levels, respectively. Therefore, in general the increase in time-mean convection over the subtropical Northern Hemisphere Pacific between WJ and SJ winters can be ascribed to the increase in the transient convective activity and is not merely a constant shift.

\section{Relationship between transient convection and circulation \\ a. Methodology}

Given the significant changes in the characteristics of the transient waves and convection over the central $\mathrm{Pa}$ cific between SJ and WJ winters, it seems appropriate to investigate the relationship between transient convection and circulation in SJ and WJ winters separately. As the source region for the equatorward-propagating waves is in the vicinity of the Asian jet (e.g., Kiladis 1998), the typical development of a transient wave train in the Asian jet during SJ and WJ winters are first compared.

A linear regression analysis was used for this purpose; for details see Kiladis and Weickmann (1992a) and Matthews and Kiladis (1999). Climatological maps of $<30$ day PKE (not shown) indicate a maximum along $30^{\circ} \mathrm{N}$ over the Asian sector, implying that maximum transient wave activity lies along this latitude. Jet streaks at $30^{\circ} \mathrm{N}$ tend to be associated with streamfunction anomalies to the south; hence, a reference time series, representative of transient wave activity in the Asian jet, was constructed from $<30$ day filtered $200-\mathrm{mb}$ streamfunction at $25^{\circ} \mathrm{N}, 115^{\circ} \mathrm{E}$. This streamfunction reference time series (the independent variable) was then regressed against the time series of an identically filtered variable of interest (the dependent variable) at each global grid point. These variables were the $200-\mathrm{mb}$ streamfunction itself, and both the zonal and meridional components of the $200-\mathrm{mb}$ wind. This procedure yields a separate regression equation between the streamfunction reference time series and the dependent variable at each grid point.

The linear dependence of the dependent variable at that particular grid point on the streamfunction reference time series is then the regressed value of that variable, for a fixed, arbitrary value of the streamfunction reference time series. The value chosen was $2 \times 10^{7} \mathrm{~m}^{2}$ $\mathrm{s}^{-1}$, a typical peak value obtained by assessing individual cases. A map of the regressed values at each grid point then gives the global pattern of the perturbation field of the dependent variable that is associated with a $2 \times 10^{7} \mathrm{~m}^{2} \mathrm{~s}^{-1}$ deviation in the streamfunction reference time series. A sequence of lagged regression maps shows the temporal evolution of the perturbation field. The statistical significance of the regression fields is discussed in the appendix.

\section{b. Development of a wave train in the Asian jet}

The sequence of lagged regression maps in Fig. 7 shows the development of $<30$ day $200-m b$ stream- function and wind vector anomalies during a WJ winter, associated with a $2 \times 10^{7} \mathrm{~m}^{2} \mathrm{~s}^{-1}$ deviation in $200-\mathrm{mb}$ streamfunction at $25^{\circ} \mathrm{N}, 115^{\circ} \mathrm{E}$. Wind vector anomalies are only shown where either the $u$ or $v$ component of the wind is locally significant at the 5\% level.

The day -2 map in Fig. 7a shows a wave train consisting of a series of anticyclonic and cyclonic perturbations lying along the Asian jet, from $30^{\circ}$ to $120^{\circ} \mathrm{E}$, and a second wave train over the North Pacific and North America. Streamfunction amplitudes equatorward of $30^{\circ} \mathrm{N}$ over the Pacific are very small at this time. The positive (anticyclonic) streamfunction anomaly at $102.5^{\circ} \mathrm{E}$ on day -2 moves eastward to the base grid point at $115^{\circ} \mathrm{E}$ by day 0 (Fig. $7 \mathrm{~b}$ ), indicating an eastward phase speed relative to the ground of approximately 7 $\mathrm{m} \mathrm{s}^{-1}$. Downstream energy dispersion is also evident; the wave train has weakened at its upstream end, over the Middle East, and strengthened downstream over the Pacific. By day +3 (Fig. 7c) there is also pronounced equatorward development of the wave train between $180^{\circ}$ and $150^{\circ} \mathrm{W}$, consistent with the large southwardpointing E-vectors in this sector during a WJ winter (Fig. 4b), and cross-equatorial dispersion near $150^{\circ} \mathrm{W}$. There is little evidence of equatorward propagation over the eastern Pacific near $120^{\circ} \mathrm{W}$, consistent with the refraction of waves away from this region and the weak E-vectors in Fig. 4b.

The equivalent regression maps for an SJ winter are shown in Fig. 8. The initial wave train along the Asian jet on day -2 (Fig. 8a) is very similar to that for the WJ winter (Fig. 7a). The wave train disperses downstream by day 0 (Fig. 8 b) in a similar manner to that described above. However, over the Pacific it then propagates equatorward and disperses across the equator into the Southern Hemisphere near $120^{\circ} \mathrm{W}$, farther to the east than in the WJ winter (Fig. 7c) and consistent with the SJ minus WJ E-vector anomaly pattern in Fig. 4c.

Therefore, the propagation characteristics of a wave train over the Asian-Pacific region are found to be different during WJ and SJ winters, with the wave train dispersing equatorward into the $180^{\circ}-150^{\circ} \mathrm{W}$ sector during a WJ winter, and into the $150^{\circ}-120^{\circ} \mathrm{W}$ sector during an SJ winter. This behavior is consistent with the basicstate changes and E-vector and PKE anomalies described in previous sections. In the next section, the relationship between these waves and ITCZ convection is investigated separately for WJ and SJ winters.

\section{c. ITCZ convection in a weak jet winter}

The sequence of lagged regression maps in Fig. 9 shows the development of $<30$ day OLR and 200-mb streamfunction and wind vector anomalies, associated with a $-40 \mathrm{~W} \mathrm{~m}^{-2}$ deviation in OLR over the base region $0^{\circ}-10^{\circ} \mathrm{N}, 160^{\circ}-150^{\circ} \mathrm{W}$, during northern winter in the four WJ winters that OLR data were available (indicated by asterisks in Table 1). The base region was chosen to cover an area with high convective variability 


\section{Weak Jet Winter}

\section{(a) Day -2}

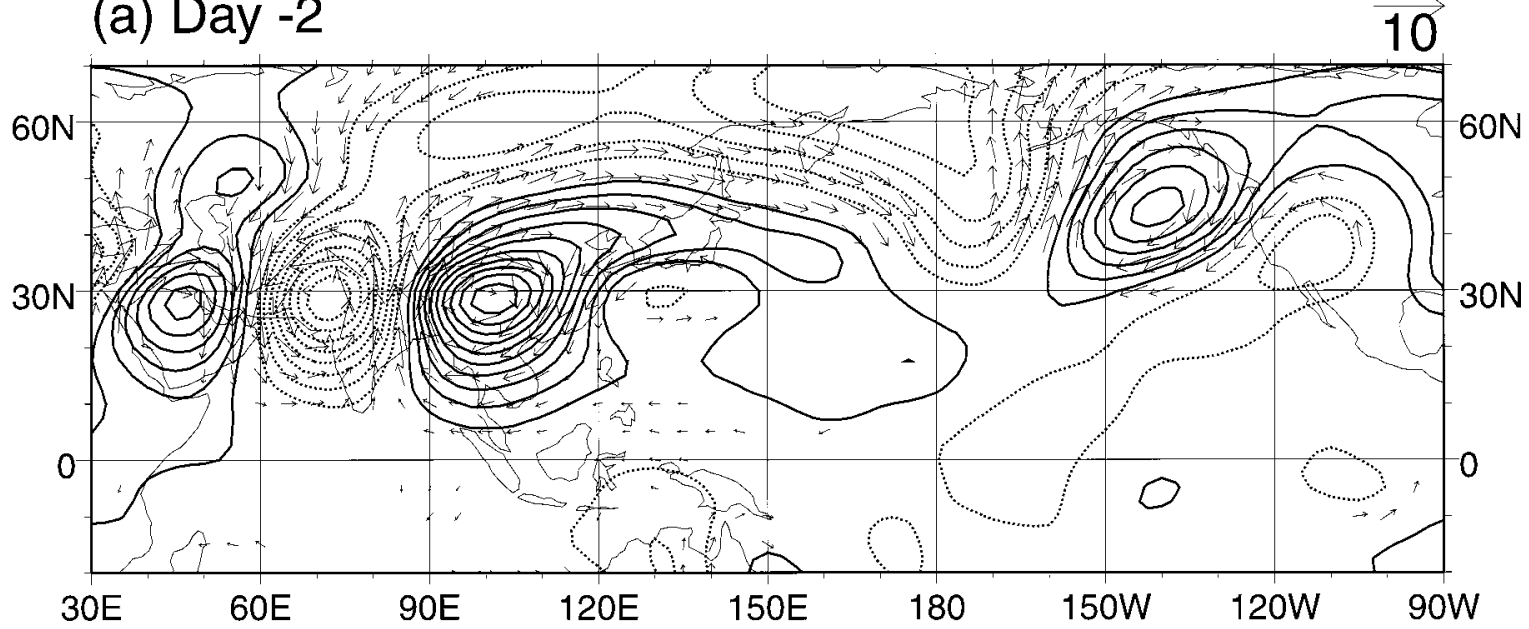

(b) Day 0

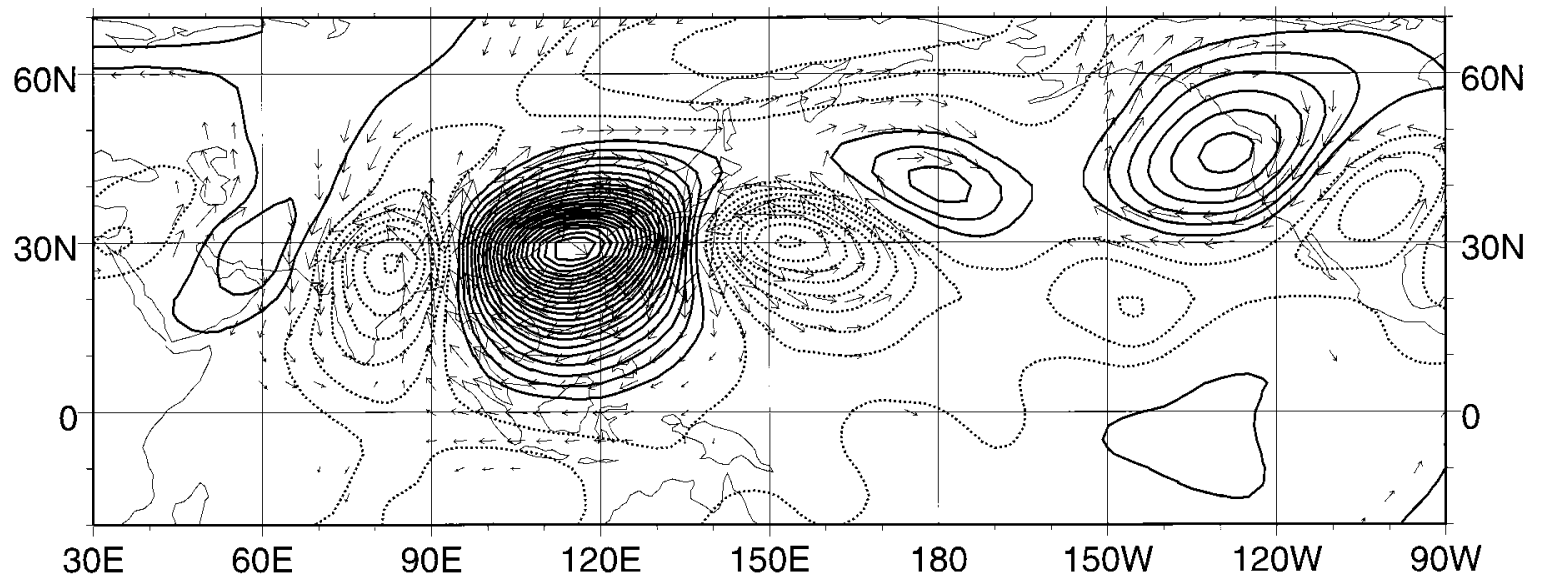

(c) Day +3

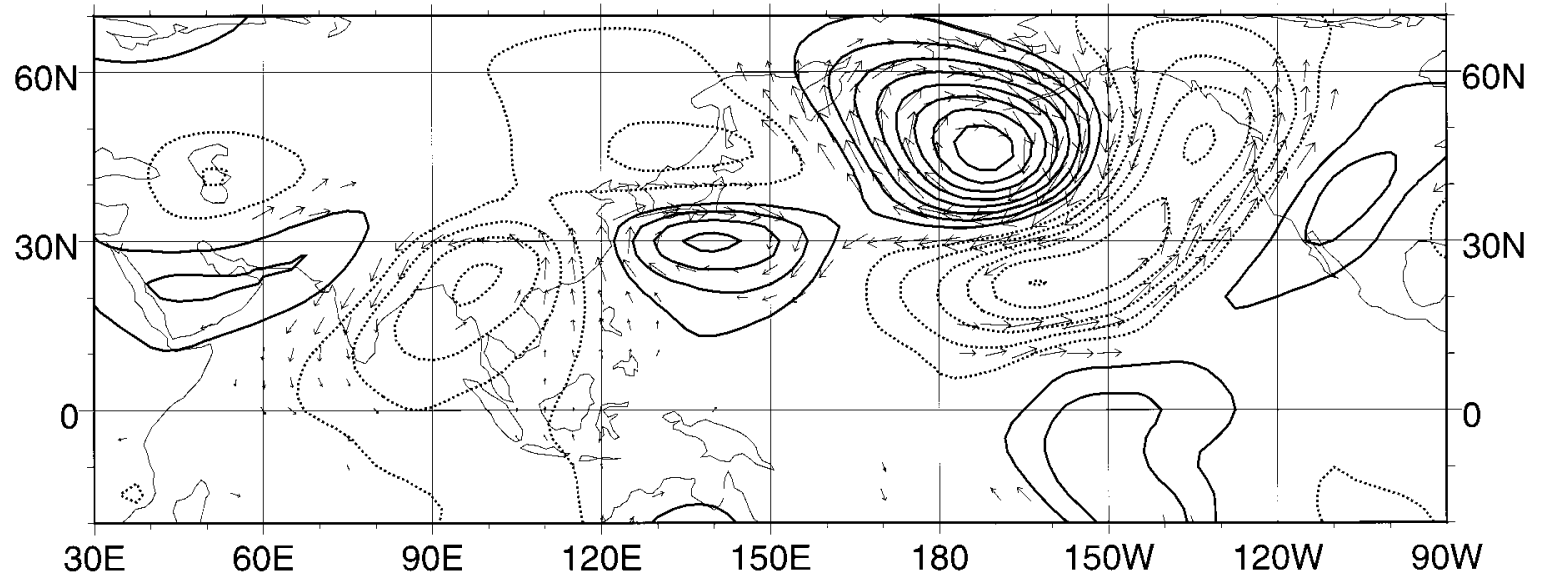

FIG. 7. The $<30$ day $200-\mathrm{mb}$ streamfunction and wind perturbations associated with a $2 \times 10^{7} \mathrm{~m}^{2} \mathrm{~s}^{-1}$ deviation in 200 -mb streamfunction at $25^{\circ} \mathrm{N}, 115^{\circ} \mathrm{E}$ during northern winter in a WJ winter: (a) day -2 , (b) day 0 , (c) day +3 . Streamfunction contour interval is $1 \times 10^{6} \mathrm{~m}^{2}$ $\mathrm{s}^{-1}$; negative contours are dashed and the zero contour is omitted. Perturbation wind vectors are shown where either the $u$ or $v$ component of the wind is locally statistically significant at the $5 \%$ level; the reference wind vector is $10 \mathrm{~m} \mathrm{~s}^{-1}$. For clarity, wind vectors are only plotted every $5^{\circ}$. 


\section{Strong Jet Winter}

(a) Day -2

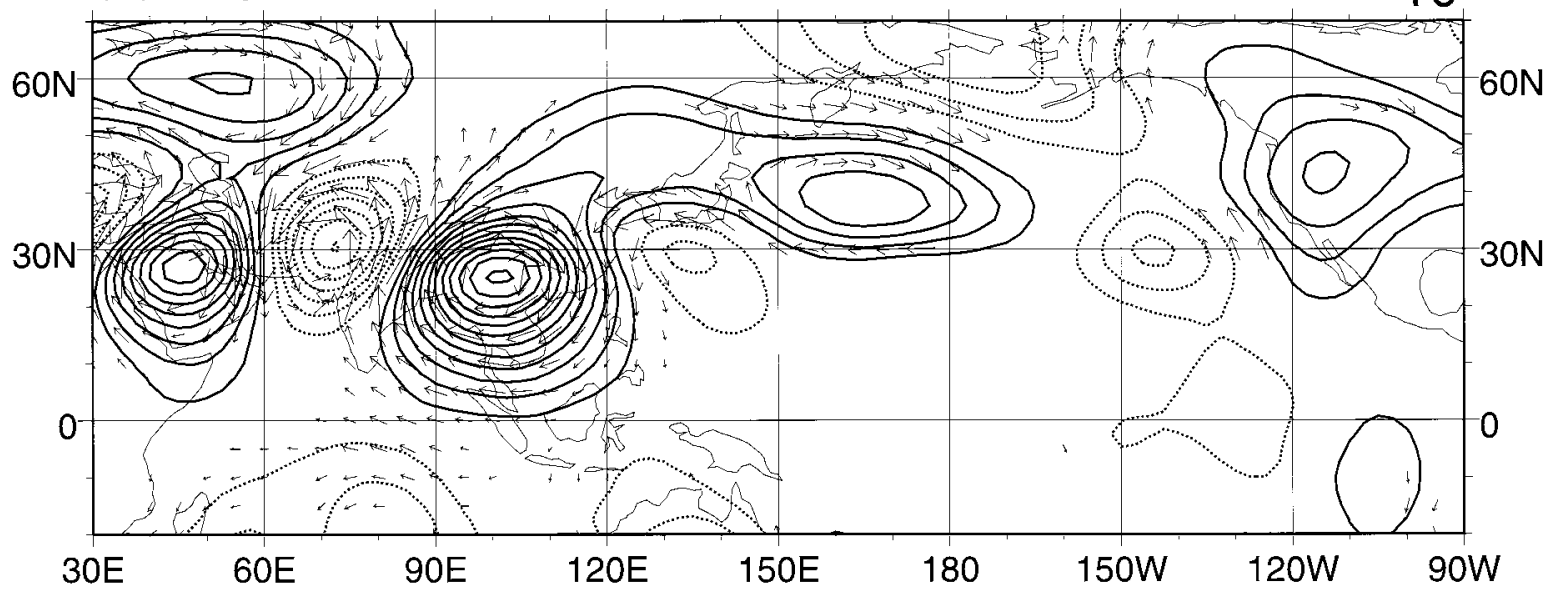

(b) Day 0

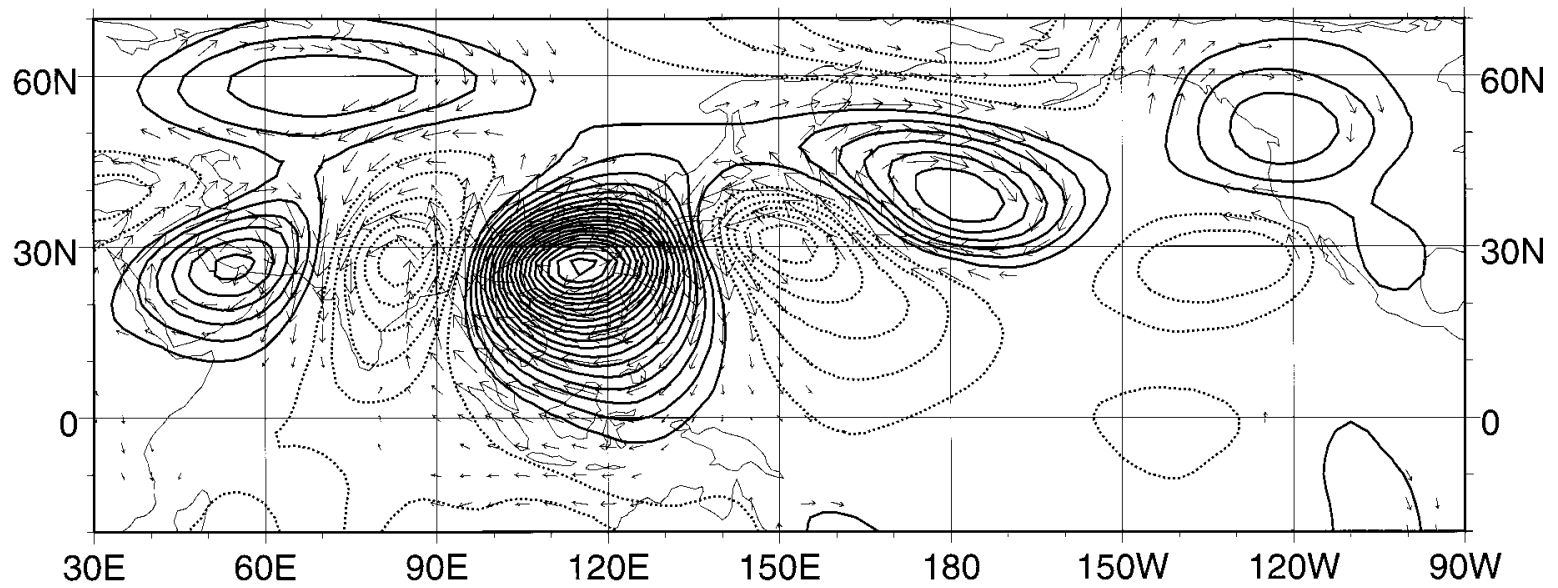

(c) Day +3

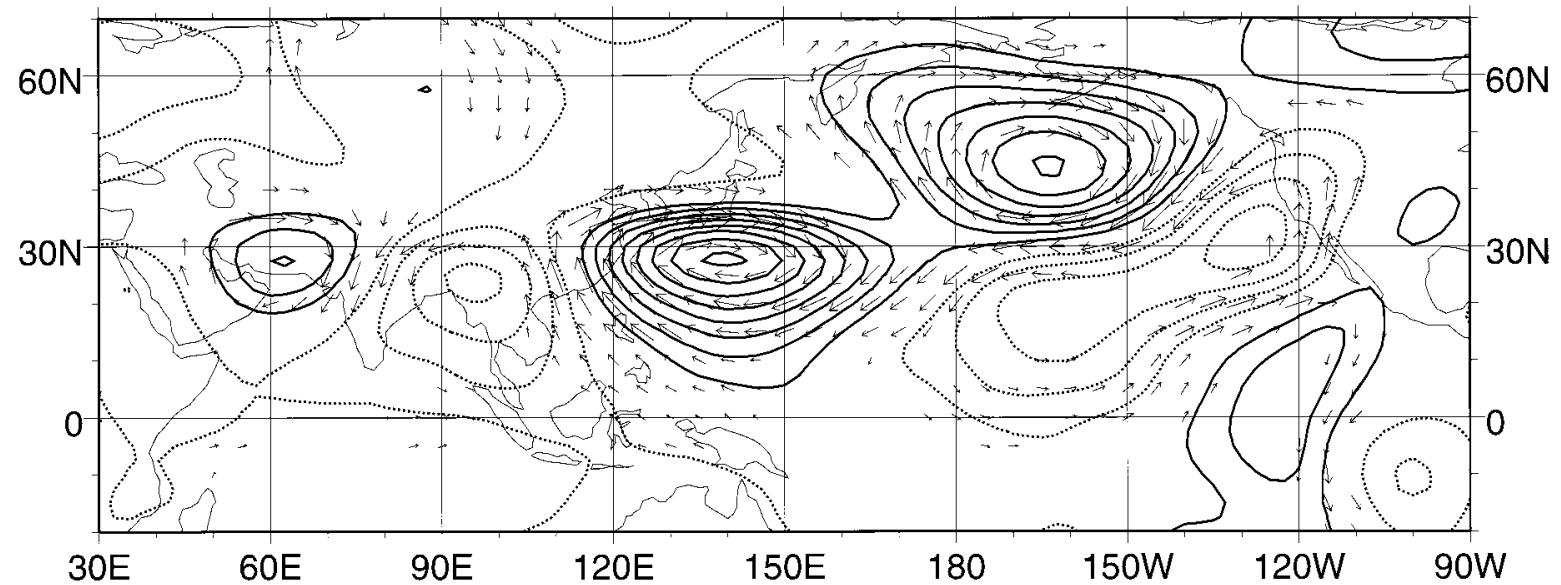

FIG. 8. As in Fig. 7 but for an SJ winter. 


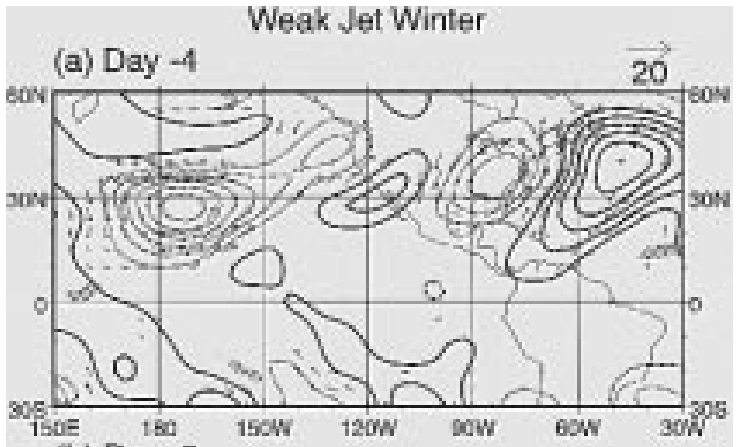

(b) Day -2

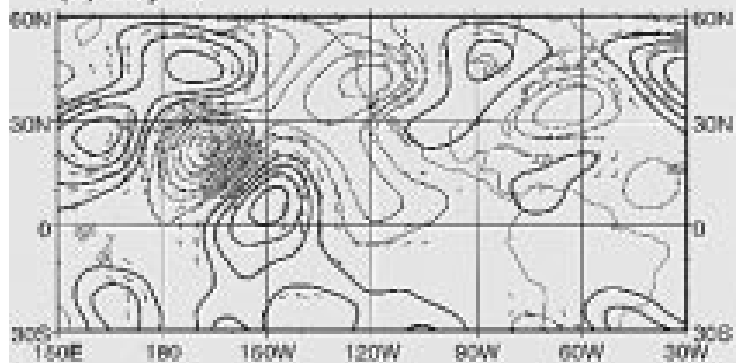

(c) Day 0

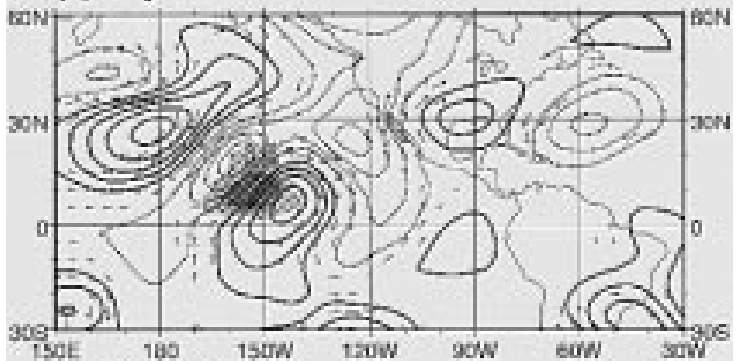

(d) Day +2

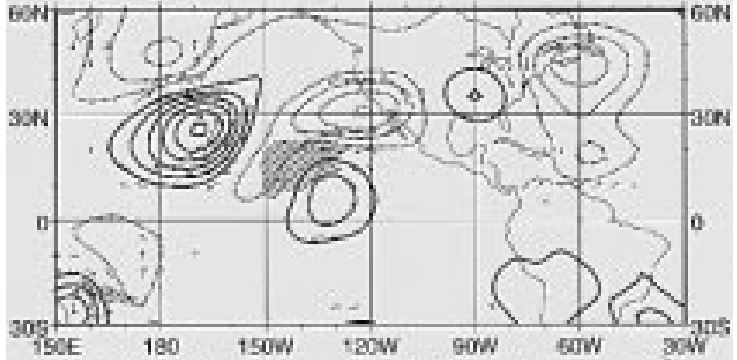

(e) 200-mb <30-day PKE, E-vectors
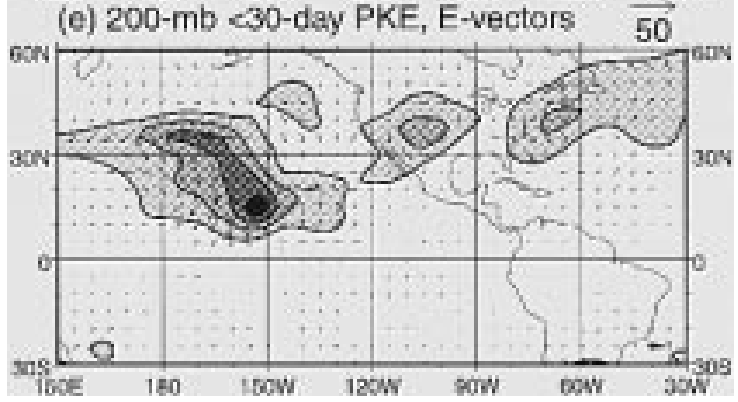

FIG. 9. The $<30$ day OLR, 200-mb streamfunction, and wind perturbations associated with a $-40 \mathrm{~W} \mathrm{~m}^{-2}$ deviation in OLR in the region $0^{\circ}-10^{\circ} \mathrm{N}, 160^{\circ}-150^{\circ} \mathrm{W}$ in a WJ winter: (a) day -4 , (b) day -2 , (c) day 0 , (d) day +2 . Streamfunction contour interval is $2 \times$ $10^{6} \mathrm{~m}^{2} \mathrm{~s}^{-1}$; negative contours are dashed and the zero contour is in both SJ and WJ winters (Fig. 5), such that a meaningful comparison of the relationship of transient convection with transient circulation can be made between SJ and WJ winters.

Four days before the OLR perturbation over the base region peaks (day -4), a cyclonic anomaly is centered at $25^{\circ} \mathrm{N}, 175^{\circ} \mathrm{W}$ (Fig. 9a). The southeastern portion of this anomaly has a southwest-northeast tilt indicating southeastward group propagation. Consistent with this tilt, an anticyclonic anomaly to the southeast at $10^{\circ} \mathrm{N}$, $150^{\circ} \mathrm{W}$ strengthens and a second cyclonic anomaly develops at $0^{\circ}, 120^{\circ} \mathrm{W}$ by day -2 (Fig. 9b). There are negative OLR anomalies, indicative of enhanced transient convection, in the poleward flow ahead of the primary cyclonic anomaly. A secondary wave train also appears to develop over the North Pacific and North America.

On day 0 (Fig. 9c) the OLR anomaly is strongest near $10^{\circ} \mathrm{N}$, at the northern edge of the base region, and there is only a small anomaly near the equator, at the southern edge of the base region. This is consistent with Fig. 5b, which indicates that the maximum in $<30$ day OLR variance lies along the ITCZ at $10^{\circ} \mathrm{N}$, with relatively little $<30$ day OLR variability along the equator over the Pacific during a WJ winter. Southeastward phase and group velocity of the wave train is also evident, consistent with the findings of Kiladis (1998).

On day +2 (Fig. 9d) a negative OLR anomaly has developed to the northeast of the base region. This cloud band appears to have been advected by the southwesterly flow ahead of the primary cyclonic anomaly. Such cloud bands are a common feature of the northern winter central and eastern Pacific (McGuirk et al. 1987, 1988; Iskenderian 1995). The regression fields on day +2 are similar to those on day -4 with opposite sign, especially over the central Pacific, reflecting the mean period of 12 days for the waves (e.g., Tomas and Webster 1994; Kiladis 1998).

Figure 9e shows the 200-mb PKE and E-vector fields calculated from the daily regression maps of $u^{\prime}$ and $v^{\prime}$, and averaged from day -6 to day +6 , that is, over approximately one cycle of the transients. The PKE field shows the region of wave activity that is associated with transient convection over the base region $0^{\circ}-10^{\circ} \mathrm{N}$, $160^{\circ}-150^{\circ} \mathrm{W}$, during a WJ winter. The southward-pointing E-vectors to the northwest of the base region, that is, near $15^{\circ} \mathrm{N}, 165^{\circ} \mathrm{W}$, are indicative of the horizontally

$\leftarrow$

omitted. OLR, where it is locally statistically significant at the $5 \%$ level, is shaded below $-15 \mathrm{~W} \mathrm{~m}^{-2}$ and $-40 \mathrm{~W} \mathrm{~m}^{-2}$. Perturbation wind vectors are shown where either the $u$ or $v$ component of the wind is locally statistically significant; the reference wind vector is $20 \mathrm{~m} \mathrm{~s}^{-1}$. For clarity, wind vectors are only plotted every $5^{\circ}$. (e) The 200-mb PKE and E-vectors, calculated from the regression maps of $u$ and $v$, and averaged from day -6 to day +6 . PKE contour interval is $25 \mathrm{~m}^{2} \mathrm{~s}^{-2}$, and values above $25 \mathrm{~m}^{2} \mathrm{~s}^{-2}$ are shaded. The reference E-vectors is $50 \mathrm{~m}^{2} \mathrm{~s}^{-2}$. 


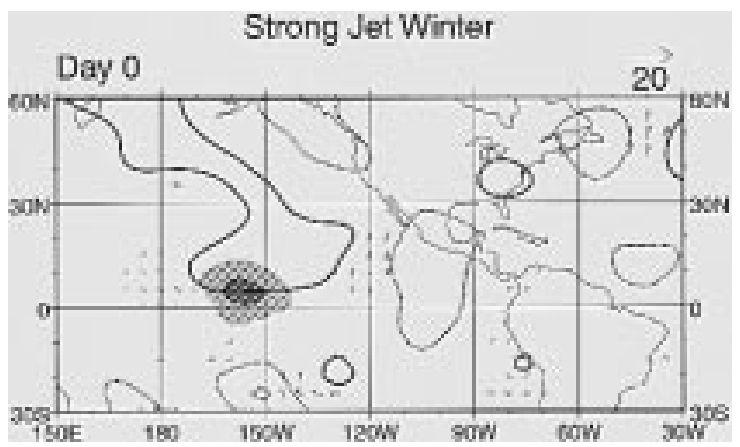

FIG. 10. As in Fig. 9 but for an SJ winter. Only the day 0 map is shown.

tilted waves that propagate equatorward in the regression maps of Figs. 9a-d. These E-vectors are similar to those in the mean field for a WJ winter in Fig. 4b. There are two other regions of large PKE and E-vector amplitude in Fig. 9e, over western North America and the western Atlantic. These represent the cumulative effects of the secondary wave train that propagates along $40^{\circ} \mathrm{N}$.

The scenario described by the transient waves and convection over the central Pacific during a WJ winter in Fig. 9 is very similar to the "climatological" scenario described over the eastern Pacific by Kiladis and Weickmann (1992b). Transient convection over the ITCZ is associated with transients that propagate equatorward and through the westerly duct. The convection apparently arises as a forced response to deep ascent in the poleward flow ahead of the troughs or cyclonic anomalies in the wave train (Kiladis 1998).

This relationship can be quantified through correlation calculations. A time series of meridional wind averaged over a $10^{\circ} \times 10^{\circ}$ box north of the ITCZ region $\left(10^{\circ}-20^{\circ} \mathrm{N}, 160^{\circ}-150^{\circ} \mathrm{W}\right)$ is used as a proxy for the equatorward-propagating waves. Maps of streamfunction regressed onto this meridional wind time series (not shown) clearly show the waves. The square of the correlation coefficient between this reference time series and time series of OLR at each grid point locally reaches 0.26 over the ITCZ region, indicating that up to $26 \%$ of the $<30$ day OLR variance can be linearly accounted for by the equatorward-propagating waves. If 6-30-day filtered data is used, this fraction of variance increases to $36 \%$.

\section{d. ITCZ convection in a strong jet winter}

The regression calculations are repeated using the same base region $0^{\circ}-10^{\circ} \mathrm{N}, 160^{\circ}-150^{\circ} \mathrm{W}$, but for the five SJ winters for which OLR data were available. The situation contrasts sharply from that in the WJ basic state; the circulation anomalies are very weak and only the zero-lagged correlation map of zonal wind is globally significant at the 5\% level (see the appendix).

Figure 10 shows the regression map at zero lag. In contrast to the WJ winter scenario, the OLR anomaly is accompanied by a weak $200-\mathrm{mb}$ anticyclonic anomaly north of the equator, associated with statistically significant easterly wind anomalies on the equator. No equatorward-propagating wave train is apparent. These circulations are more in line with a local response to an equatorial diabatic heating, rather than an extratropical forcing for the convection, such as is normally seen in regions of mean upper-tropospheric easterly flow (Kiladis and Weickmann 1997). The 200-mb PKE and E-vector fields, averaged from day -6 to day +6 (not shown), are extremely weak and show no coherent signal.

\section{Numerical experiments}

\section{a. Model description}

To further investigate the different behavior of the transients over the Pacific during SJ and WJ winters, a numerical model study is undertaken. The model used was the spectral transform, global primitive equation model of Hoskins and Simmons (1975), run with $12 \sigma$ levels in the vertical, and at T42 horizontal resolution. Damping processes were represented by a Newtonian cooling with timescales of $(9 \times 10,9,8,7)$ and $(4,6$, $10,18,5 \times 25,18,12,8)$ days, respectively, on the zonal and wave components at the 12 model levels. A $\nabla^{6}$ hyperdiffusion operating with a timescale of $4 \mathrm{~h}$ on the smallest resolvable scale, and a boundary layer drag with timescales of 4 and 1.5 days on the lowest two levels were also included, following Hoskins and Jin (1991).

The model was linearized about a three-dimensional time-mean basic state, calculated from the NCEPNCAR reanalyses. As this basic state was not a steadystate solution of the model, a constant forcing term was applied to make it so. This forcing term was calculated by initializing the model with the basic state then running it for one time step and calculating the tendencies (i.e., the model time derivatives of the basic state). The negative of these tendencies are then applied as a constant forcing term at each time step during the integration to keep the initial basic state constant. They are effectively a crude parametrization of all processes that are not included in the model, such as the effects of orography, radiation, mean convective heating, and the time-mean forcing by the transients.

An initial value perturbation can then be added to the basic state and the time evolution of this perturbation on the basic state can be seen by integrating the model forward (section 6b). Alternatively, an anomalous heating can be superimposed on the basic state, and the response to this heating can be seen by integrating the model forward (section 6c). These methods have been used previously by Hoskins and Jin (1991) and Jin and Hoskins (1995), respectively. 


\section{b. Initial value experiments}

\section{1) INITIAL VALUE PERTURBATION}

A series of initial value experiments was designed to further examine the effect of changes to the basic state on the equatorward propagation of transients over the Pacific. The source of these waves appear to be perturbations in the African-Asian jet (Figs. 7a and 8a). Therefore, an idealized vorticity perturbation was created with zonal wavenumber 6 horizontal structure modulated by an elliptical envelope centered at $25^{\circ} \mathrm{N}, 15^{\circ} \mathrm{E}$ with semimajor axis of $180^{\circ}$ longitude and semiminor axis of $10^{\circ}$ latitude. This structure describes a wavepacket of approximately 1.5 wavelengths (Fig. 11a). The vertical structure was confined to the upper troposphere, peaking near $250 \mathrm{mb}$, in agreement with observations (not shown).

A temperature perturbation in geostrophic balance with the vorticity perturbation was computed, and these temperature and vorticity perturbations were then recalculated using an interative procedure (Hoskins and Simmons 1975) to produce a balanced perturbation with zero divergence tendency when superimposed on a resting atmosphere. This "balanced" perturbation was then superimposed on the three-dimensional basic state, and the model was integrated forward in time as an initial value problem. As the basic state was maintained by a constant forcing term, the subsequent anomaly fields describe the linear dispersion and development of the initial wavepacket in the African jet on the three-dimensional basic state. The procedure described above only produced a partially balanced wavepacket, and the first few days of the integration were characterized by a further balancing of the perturbation by gravity wave adjustment. By about day 12 this adjustment was essentially complete and only a slowly varying wave train in quasigeostrophic balance remained. The location of the initial wavepacket was centered at $25^{\circ} \mathrm{N}, 15^{\circ} \mathrm{E}$ to be sufficiently far upstream such that the wave train was in approximate quasigeostrophic balance when it reached the Pacific region.

\section{2) Results}

The first experiment used a global three-dimensional basic state calculated from the mean of the seven WJ winters listed in Table 1. Figures $11 \mathrm{~b}-\mathrm{d}$ show the uppertropospheric streamfunction and divergence perturbations on selected days of this integration with the WJ basic state. The basic-state zonal wind has been contoured at $40 \mathrm{~m} \mathrm{~s}^{-1}$ (thick line) and zero (thicker line) to show the extent of the subtropical jet and the equatorial easterlies/westerly duct, respectively.

On day 12 (Fig. 11b) the wave train is propagating over the Pacific along the jet. The cyclonic anomaly centered at $30^{\circ} \mathrm{N}, 165^{\circ} \mathrm{E}$ shows little horizontal tilt. However, by day 15 (Fig. 11c) this cyclonic anomaly has moved to $25^{\circ} \mathrm{N}, 180^{\circ}$ and has developed a south- west-northeast tilt. Consistent with this tilt, the wavepacket has begun to disperse southeastward such that a weak anticyclonic anomaly has developed near the equator at $150^{\circ} \mathrm{W}$. Upper-level divergence can be seen in the poleward flow at $15^{\circ} \mathrm{N}, 160^{\circ} \mathrm{W}$ ahead of the cyclonic anomaly (and associated upper-level trough). This circulation and divergence pattern looks remarkably similar to the observed pattern 4 days before transient convection peaks over the ITCZ (Kiladis 1998; Fig. 9a in this paper).

Four days later, on day 19 (Fig. 11d) of the integration, the wave train has dispersed southeastward across the equator into the Southern Hemisphere. There is now a large region of upper-level divergence along $10^{\circ} \mathrm{N}$ (the latitude of the ITCZ) from $170^{\circ}$ to $145^{\circ} \mathrm{W}$. The pattern closely resembles the observed pattern when convection peaks over the ITCZ (Kiladis 1998; Fig. 9c in this paper) and is further evidence for transient ITCZ convection being dynamically forced by equatorward-propagating waves during northern winter. It should be noted that there is no representation of the transient convection in the model and the patterns are produced purely by dry wave dynamics.

The period of the waves is approximately 14 days (e.g., the cyclonic anomaly at $30^{\circ} \mathrm{N}, 165^{\circ} \mathrm{E}$ on day 12 of the integration is approximately out of phase with the anticyclonic anomaly over the same region 7 days later on day 19). This is in close agreement with a period of approximately 12 days for the observed waves (Kiladis 1998).

A second integration was performed with an identical initial wavepacket, but on an SJ basic state (Figs. 11eg). On day 12 (Fig. 11e) the wave train is very similar to that in the WJ experiment (Fig. 11b). However, it subsequently evolves differently, which can only be attributed to the change in the SJ basic state, in particular the extended Pacific jet and weakened westerly duct. Consistent with the observational results shown in Fig. $8 \mathrm{c}$, the equatorward and cross-equatorial propagation of the wave train on days 15 and 19 (Figs. 11f,g) is farther east when compared to the integration on the WJ basic state. The cross-equatorial propagation is also much weaker, and there are no large divergence anomalies within $10^{\circ}$ of the equator.

Finally, a third integration was performed with a three-dimensional basic state taken from the single winter of 1997/98. This El Niño winter had the largest positive value of the ZWI over the $30-y r$ period (Fig. 1) and the time-mean 200-mb equatorial easterlies extended almost across the entire Pacific, with only a very narrow region of weak westerly flow from $125^{\circ}$ to $100^{\circ} \mathrm{W}$. The day 19 perturbations show no cross-equatorial propagation at all and the wave train is confined to the Northern Hemisphere (Fig. 11h).

\section{c. Heating experiments}

A separate series of experiments is now described that investigates the role of the seasonal-mean anoma- 


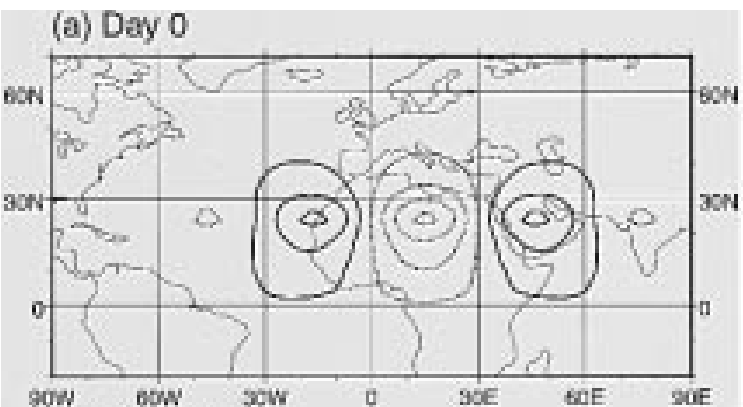

(b) WJ: Day 12

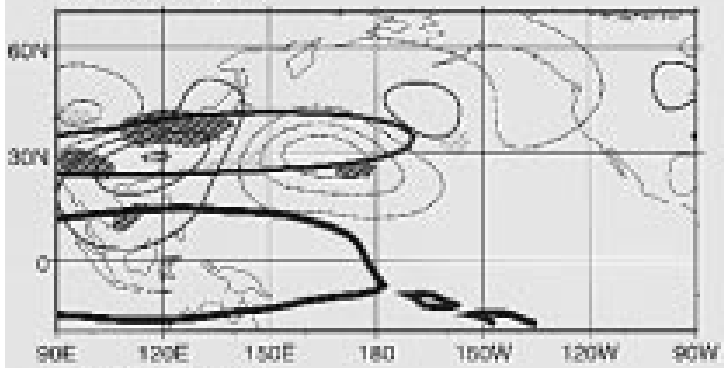

(c) WJ: Day 15

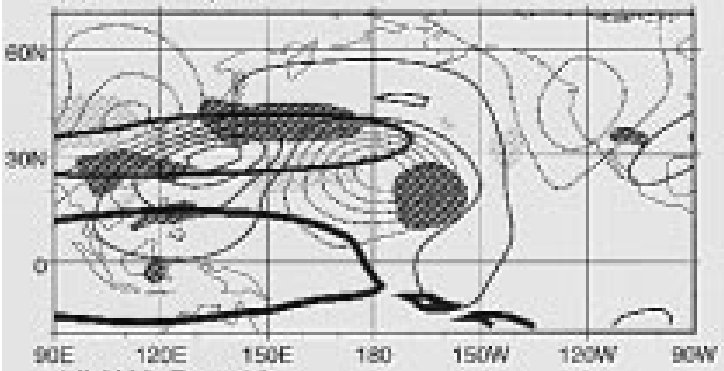

(d) WJ: Day 19

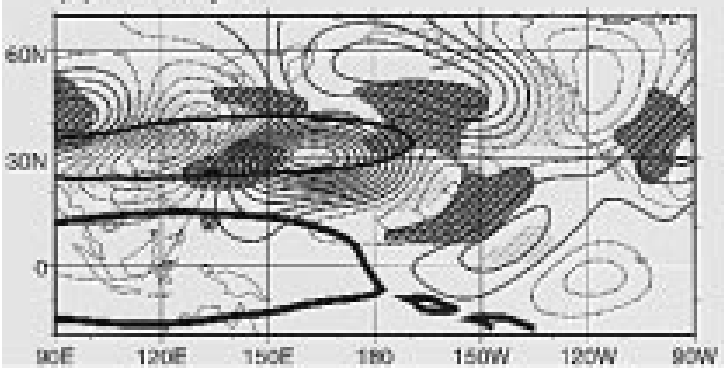

(e) SJ: Day 12

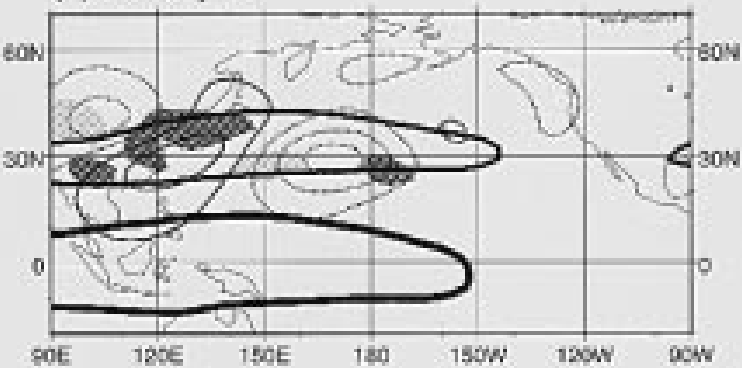

(f) S: Day 15

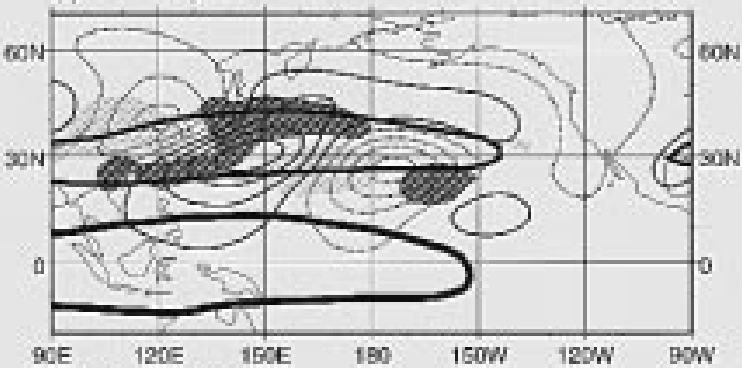

(g) SJ: Day 19

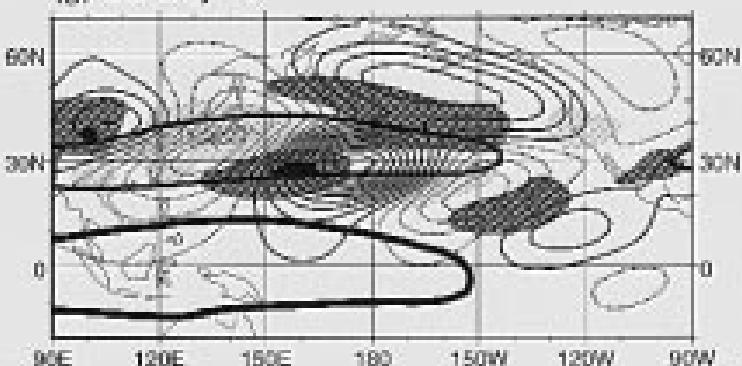

(h) DJF 1997/98: Day 19

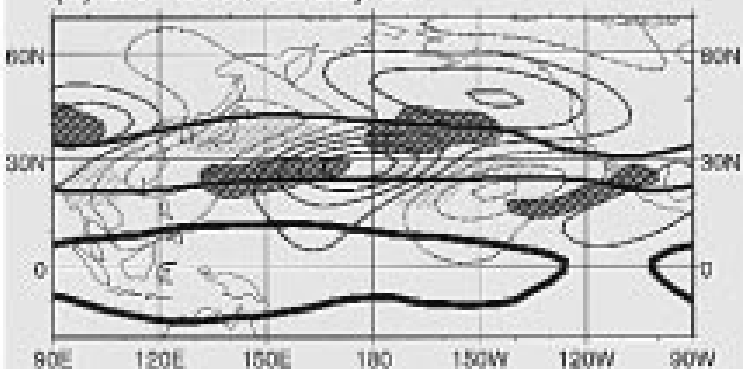

FIG. 11. The 191-mb streamfunction and divergence perturbations from the initial value integrations. (a) The initial (day 0) wavepacket in the African jet used in all three integrations. Note the longitudinal domain is different from the following diagrams. (b)-(d) The perturbations over the Pacific region on days 12, 15, and 19 of the integration with the WJ basic state. The basic-state zonal wind is contoured at $40 \mathrm{~m}$ $\mathrm{s}^{-1}$ (thick line) and zero (thicker line). (e)-(g) As in (b)-(d) but for the SJ basic state. (h) Day 19 perturbations for the DJF 1997/98 basic state. Divergence is shaded darkly above $2 \times 10^{-7} \mathrm{~s}^{-1}$ and slightly below $-2 \times 10^{-7} \mathrm{~s}^{-1}$. Streamfunction contour interval is $5 \times 10^{5} \mathrm{~s}^{-1}$; first positive contour is at $2.5 \times 10^{5} \mathrm{~m}^{2} \mathrm{~s}^{-1}$ and negative contours are dotted. 


\section{$400-\mathrm{mb} \mathrm{H}$}

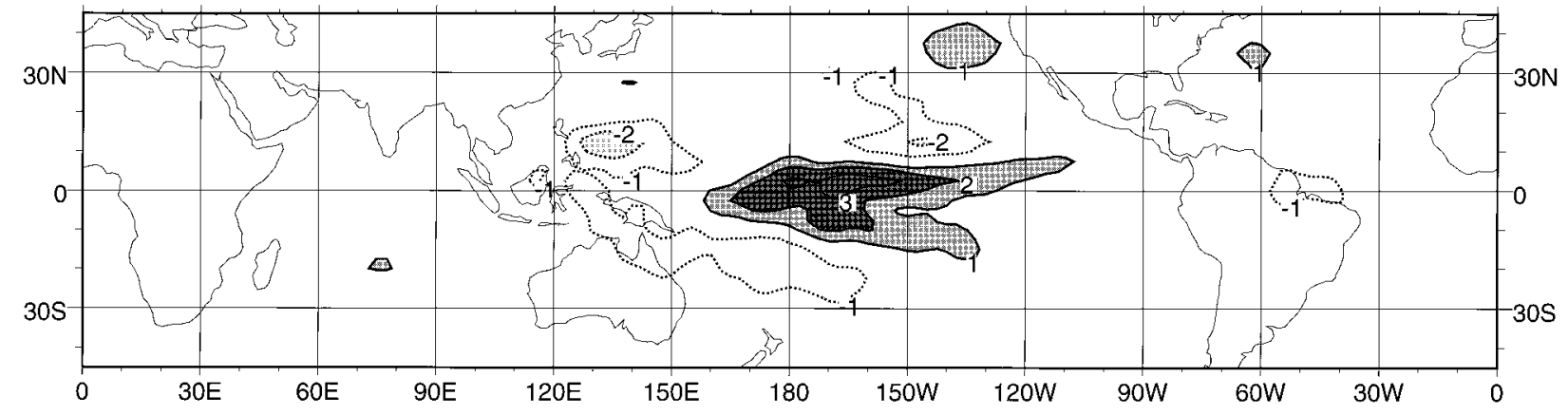

FIG. 12. The 400-mb diabatic heating composite mean. SJ - WJ winter. Contour interval is $1 \mathrm{~K}^{\text {day }}{ }^{-1}$; positive (negative) contours are

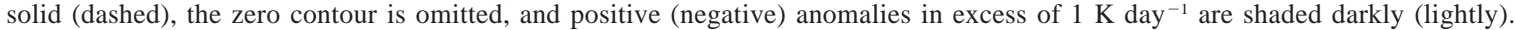

lous heat source that arises from the change in transient convection over the ITCZ. The SJ minus WJ basic-state anomalies such as those in the 200-mb zonal wind difference field in Fig. 2c arise from a combination of factors. A portion of this flow arises as a direct response to the seasonal-mean tropical convective heating associated with equatorial Pacific SST anomalies during the ENSO cycle. Such a response includes anomalous upper-tropospheric anticyclones on either side of the equator (e.g., Jin and Hoskins 1995). The westerly flow on the poleward flank of the anticyclones leads to an extension of the subtropical jets over the Pacific. This initial change to the basic state can then lead to an increase in transient wave activity along the extended jet and to a reduction in equatorward-propagating transients as shown in Fig. 4. In addition, the forcing of the mean flow from the vorticity fluxes of these anomalous transients also acts to extend the Pacific jet (Hoerling and Ting 1994), consistent with the response to the equatorial SST anomalies. The mean flow forcing by the anomalous transient vorticity fluxes was found to be approximately five times the magnitude of the mean flow forcing by the direct response to the equatorial SST anomalies (Hoerling and Ting 1994); therefore, wavemean flow interactions are of primary importance in determining the extratropical basic-state flow anomalies.

In the present study an added ingredient has been introduced. In section $3 \mathrm{c}$, the existence of a secondary negative seasonal-mean deep convective anomaly over the tropical Northern Hemisphere central Pacific (centered at $15^{\circ} \mathrm{N}, 135^{\circ} \mathrm{W}$ ) of opposite sign to the primary positive seasonal-mean convective anomaly over the equatorial central Pacific during an SJ winter was established (Fig. 3c). It was hypothesized that this secondary negative seasonal-mean convective anomaly was due to the decrease of equatorward-propagating transients (Fig. 4) and their associated transient convection over the central Pacific (Figs. 5, 6) during an SJ winter. This secondary convective anomaly will have a (negative) seasonal-mean heat source anomaly associated with it, which will in turn have a far-field response. As this secondary heating anomaly is of opposite sign to the primary, equatorial heating anomaly, its response will also be of opposite sign; that is, it will offset the response to the primary heating anomaly associated with the equatorial SST perturbations.

Given the complexity of the feedbacks outlined above, a full attempt to predict the changes to the basic state is not attempted here. Instead, some simple experiments are performed to estimate the first-order effect of the secondary seasonal-mean heating anomaly.

\section{1) Diabatic heating Anomaly}

First the seasonal-mean diabatic heating anomalies are calculated. While OLR is a useful proxy for deep tropical convection as it effectively measures cloud-top temperature, it is not a measure of the actual heating rate or the vertical structure of the heating profile. Therefore the heating rate $H$ at $400 \mathrm{mb}$ was estimated directly from the NCEP-NCAR reanalysis data itself, as a residual in the thermodynamic equation:

$$
\frac{\partial \theta}{\partial t}+u \frac{\partial \theta}{\partial x}+v \frac{\partial \theta}{\partial y}+\omega \frac{\partial \theta}{\partial p}=\left(\frac{p_{0}}{p}\right)^{R / C_{p}} H .
$$

Daily mean values of $\theta, u, v$, and $\omega$ were retrieved for the 500-, 400-, and 300-mb levels; the differentials were calculated by finite differences, and $H$ was then calculated in order to balance the thermodynamical equation (4). In the Tropics, the primary balance is between adiabatic cooling by ascent (the $\omega \partial \theta / \partial p$ term) and the diabatic heating; hence, an accurately determined vertical (pressure) velocity or divergent wind field in the reanalysis is desirable. For a detailed discussion see Yanai and Tomita (1998), who concluded that the NCEP-NCAR reanalysis thermodynamical fields were suitably accurate for time-mean estimates of $H$.

Figure 12 shows the SJ minus WJ composite seasonal-mean $400-\mathrm{mb} H$ field. The high spatial correlation with the SJ minus WJ OLR field of Fig. 3c is apparent. The heating pattern of Fig. 12 was then used as a steady diabatic heat source in the primitive equation model. The vertical profile of the heating followed that of Jin 
(a) Equatorial central Pacilic heating

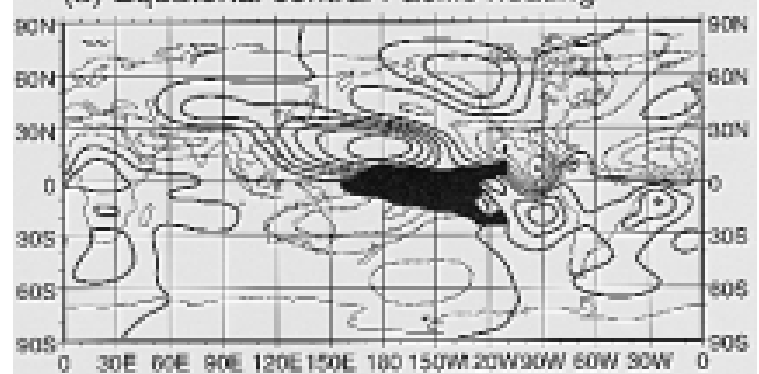

(b) NH central Pacific cooling

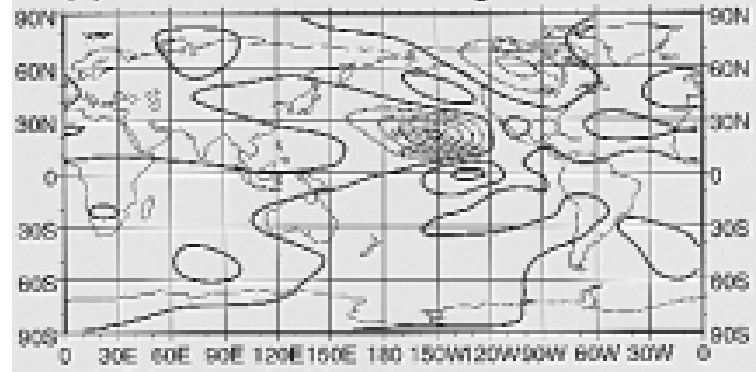

(c) Other tropical heating

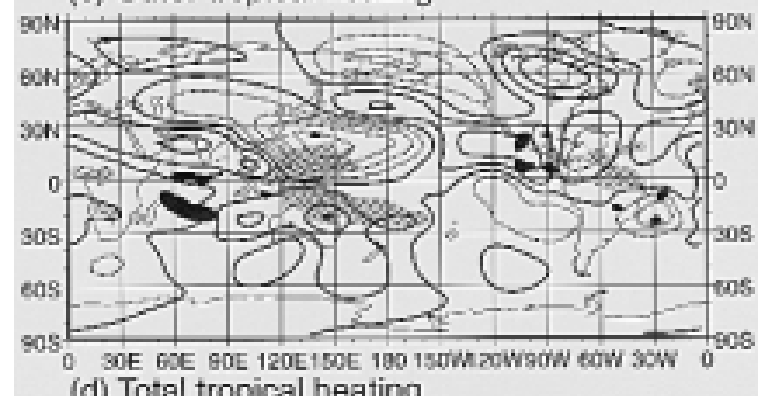

(d) Total tropical heating

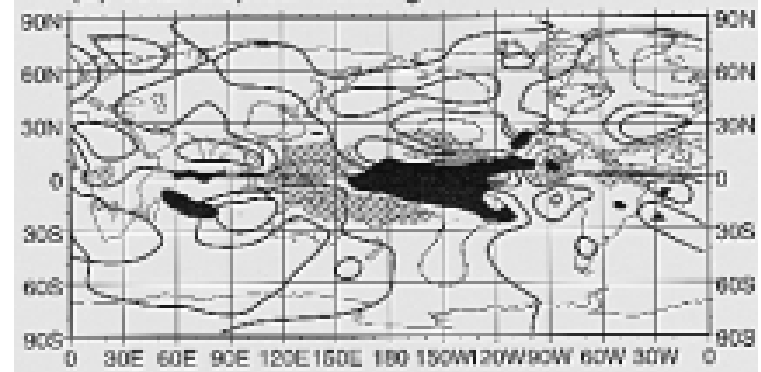

(c) Observations

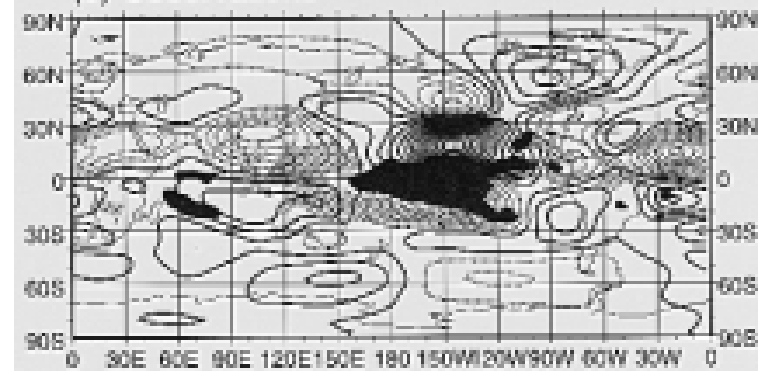

FIG. 13. Day 15 246-mb zonally asymmetric streamfunction perturbation to SJ - WJ heating fields. (a) Equatorial central Pacific heating (positive heating from $25^{\circ} \mathrm{S}-25^{\circ} \mathrm{N}, 150^{\circ} \mathrm{E}-110^{\circ} \mathrm{W}$ ) only. (b) Northern Hemisphere central Pacific cooling (negative heating from $0^{\circ}-25^{\circ} \mathrm{N}, 180^{\circ}-110^{\circ} \mathrm{W}$ ) only. (c) Other tropical heating $\left(25^{\circ} \mathrm{S}-25^{\circ} \mathrm{N}\right)$. (d) Total tropical heating (a)+(b)+(c). (e) Observed SJ - WJ 200- and Hoskins (1995), peaking near $400 \mathrm{mb}$. This was in agreement with observations of deep tropical convection (e.g., Yanai et al. 1973) and the time-mean vertical profile of heating in the NCEP-NCAR reanalysis (Yanai and Tomita 1998).

\section{2) Results}

The total heating field of Fig. 12 was partitioned geographically into three regions, and the linear response to each of these three steady heat sources was assessed in separate integrations.

In the first integration, only the positive steady heat source associated with the positive SST anomalies over the equatorial central Pacific was superimposed on the model, which was integrated forward in time. The resulting anomalous circulation can be viewed as the direct linear response of the atmosphere to this steady diabatic heat source. The climatological-mean basic state is baroclinically unstable, but the amplitude of baroclinic waves remained negligible for the first 20 days of the integration, by which time the direct response to the diabatic heat source was firmly established over the globe. This technique has been used in many previous studies (e.g., Jin and Hoskins 1995; Matthews et al. 1996).

Figure 13a shows the linear response at day 15 in the 246-mb streamfunction field to the positive heating anomalies over the tropical central Pacific $\left(25^{\circ} \mathrm{S}-25^{\circ} \mathrm{N}\right.$, $150^{\circ} \mathrm{E}-110^{\circ} \mathrm{W}$ ). The total response is dominated by an equatorial Kelvin wave that spans the entire longitudinal domain; for clarity the zonal-mean response has been subtracted. A pair of anomalous subtropical anticyclones lie alongside and to the west of the heating anomaly; these can be interpreted as an equatorial Rossby wave response (Jin and Hoskins 1995). An extratropical wave train has been established over the North Pacific and North America. With its cyclonic, anticyclonic, and cyclonic centers over the North Pacific, Canada, and eastern North America, respectively, this has a strong projection onto the Pacific-North American (PNA) pattern (Barnston and Livezey 1987).

This initial direct response to the positive equatorial SST anomalies during a warm event includes easterly anomalies on the equator and hence an eastward expansion of the region of mean easterlies over the western Pacific, and the westerly anomalies of up to $15 \mathrm{~m} \mathrm{~s}^{-1}$ near $30^{\circ} \mathrm{N}, 180^{\circ}$ are in phase with an extension of the Pacific jet. These changes to the basic state can contribute to changes in the transient circulation and con-

$\leftarrow$

$\mathrm{mb}$ zonally asymmetric streamfunction. Streamfunction contour interval is $2 \times 10^{6} \mathrm{~m}^{2} \mathrm{~s}^{-1}$; negative contours are dashed. Positive heating anomalies (at the $\sigma=0.38$ level) above $+0.5 \mathrm{~K} \mathrm{day}^{-1}$ are shaded darkly and negative anomalies below $-0.5 \mathrm{~K}$ day $^{-1}$ are shaded lightly. 
vection, ultimately leading to the secondary region of negative seasonal-mean heating anomalies over the Northern Hemisphere tropical central Pacific.

In the second integration, the direct response to this negative steady heating anomaly alone is calculated. The response takes the form of a cyclonic anomaly centered approximately over the negative heating anomaly (Fig. 13b). The easterlies on the poleward flank of this cyclonic anomaly in the vicinity of $30^{\circ} \mathrm{N}, 150^{\circ} \mathrm{W}$ have a magnitude of approximately $10 \mathrm{~m} \mathrm{~s}^{-1}$ and significantly offset the westerly anomalies attributed to the positive SST anomalies in Fig. 13a. Similarly, the westerly anomalies (of magnitude $15 \mathrm{~m} \mathrm{~s}^{-1}$ ) on the equatorward flank of the cyclonic anomaly in Fig. 13b partially offset the equatorial easterly anomalies in Fig. 13a. Hence it appears that the first-order effect of the secondary negative steady heating anomaly attributed to the change in the transients is to reduce the initial changes in the basic state that brought about that change in the transients, that is, a negative feedback. The extratropical response over the North Pacific and North America to the negative heating anomaly in Fig. $13 \mathrm{~b}$ is also approximately out of phase with the response to the positive central equatorial Pacific heating in Fig. 13a.

In Fig. 13c the response to the remainder of the SJ minus WJ tropical heating field is shown. The largest component of this field is the negative heating anomaly over the western Pacific, and the response takes the form of an upper-tropospheric cyclonic anomaly in the Northern Hemisphere centered slightly to the east of the heating. This also significantly offsets the Pacific jet extension and the equatorial easterly anomalies over the western Pacific from the positive equatorial central Pacific heating in Fig. 13a. Here the extratropical response is approximately in quadrature with that in Fig. 13a.

The day 15 linear response to the total SJ minus WJ heating field (Fig. 13d) is the sum of Figs. 13a-c. The jet extension in Fig. 13a has disappeared and there are actually easterly anomalies near $30^{\circ} \mathrm{N}, 150^{\circ} \mathrm{W}$. Westerly anomalies extend across the eastern Pacific along $15^{\circ} \mathrm{N}$. For comparison, the observed SJ minus WJ 200-mb streamfunction field is shown in Fig. 13e. It is very different from the linear response to the total heating field (Fig. 13d). In fact the subtropical anticyclone pair over the central Pacific and the extratropical features over the Pacific and North America (PNA pattern) closely resemble the response to the equatorial central Pacific heating alone (Fig. 13a). These features are very weak or missing entirely from Fig. 13d.

This series of numerical experiments shows that the global circulation anomalies during the ENSO cycle are far more than just a simple response to tropical heating anomalies, in agreement with other studies. As a first step in determining the causes of these circulation anomalies, it has been shown that the linear response to the negative heating anomalies over the Northern Hemisphere tropical Pacific is not negligible, as they largely offset the response to the "classical" positive heating anomalies over the equatorial central Pacific.

\section{Summary and discussion}

The interannual variability of transient waves and convection over the central and eastern Pacific has been studied using the NCEP-NCAR reanalysis and satellite OLR data. Northern winters with an extended Pacific jet were characterized by a weakening of the equatorial upper-tropospheric westerlies over the central and eastern Pacific together with an eastward expansion of the equatorial upper-tropospheric easterlies over the western Pacific. Weak jet winters were characterized by anomalies in the opposite sense. A strong correlation was found between jet strength and the ENSO cycle, such that strong jet (SJ) winters corresponded to warm events or the El Niño phase of ENSO and weak jet (WJ) winters corresponded to cold events or La Niñas.

Consistent with the changes to the basic state and barotropic Rossby wave theory, in SJ winters transients were found to propagate preferentially along the extended Pacific jet, which formed an almost continuous waveguide across the North Pacific. During WJ winters, the transients tended to be refracted equatorward over the central Pacific, away from the discontinuous subtropical jet and toward the strengthened and expanded equatorial westerly duct. This behavior was simulated in initial value experiments with a multilevel primitive equation model. Similar behavior of a Rossby wavepacket in El Niño and La Niña basic states was found in a barotropic model by Ambrizzi (1994) and in a baroclinic model by Hendon (1986).

As transient convection over the ITCZ region of the central and eastern Pacific is forced by such equatorward-propagating transients during northern winter (Kiladis and Weickmann 1992a,b, 1997; Kiladis 1998) a change in the transient circulation was found to lead to a change in the transient convection. During WJ (SJ) winters, the transient convection increased (decreased), consistent with the increase (decrease) in equatorwardpropagating transients. This change in behavior is so marked that the relationship between the transient circulation and tropical convection was entirely different over a region of the central Pacific, such that during a WJ winter (or La Niña) transient convection over the tropical central Pacific near $150^{\circ} \mathrm{W}$ was associated with equatorward-propagating transients as described above. However, during an SJ winter (or El Niño) this relationship broke down almost completely. Transient convection over the same area was not clearly associated with any extratropical circulation; instead it appeared to be associated with a weak equatorial Rossby wave circulation, behavior that is more like that typically found over the western Pacific during northern winter.

The reduction in transient convection over the ITCZ region during an SJ winter appeared to project onto the longer seasonal-mean timescale, such that during an SJ 
winter there was a seasonal-mean negative convection anomaly over the ITCZ region over the central Pacific, of opposite sign to the primary positive convective anomaly over the equatorial central Pacific associated with the anomalously warm SSTs there. The situation was reversed during a WJ winter. The negative skewness of unfiltered daily mean OLR time series over the ITCZ region indicated that the change in seasonal-mean convection between SJ and WJ winters was mainly caused by the change in transient convection.

However, a portion of the change in seasonal-mean convection did appear to be unrelated to changes in the transients. A posssible mechanism for this portion of the negative convective anomaly over the ITCZ during an SJ winter has been proposed by Hosaka et al. (1998). In their model, a negative off-equatorial convective anomaly was due to frictional moisture divergence in the boundary layer in response to the enhanced steady convection over a positive equatorial SST anomaly.

The linear response to the seasonal-mean diabatic heating anomalies in the SJ and WJ winters was calculated using a primitive equation model. The direct response to the positive heating anomalies over the central equatorial Pacific was found to be offset to some extent by the negative heating anomaly of the weakened ITCZ north of the equator during SJ winters. However, the direct response to equatorial heating anomalies can be considered as a first step in a complex series of interactions between the time-mean forcing and the transients. As the basic state changes by a direct response to SST-induced atmospheric heating, the propagation characteristics of the transients will also change. Together with the nonlinear part of the response to the anomalous heating, these components will act to further change the basic-state circulation and its Rossby wave propagation characteristics.

Therefore, if a GCM is to simulate the ENSO cycle, a necessary criterion is that it must accurately represent the relationship between transient circulation and convection that is observed over the central and eastern Pacific, with convection being forced in the region of ascent and reduced static stability ahead of troughs in equatorward-propagating wave trains. GCMs can certainly simulate this relationship (Slingo 1998), although the basic state, and in particular the strength of the jet, must be correct in order to obtain the correct propagation characteristics of the transients (Reynolds and Gelaro 1997). However, the ability of a GCM to accurately simulate another key link in this complex feedback network, that of the forcing of the mean flow by the transient vorticity fluxes, is questionable (Hoerling and Ting 1994).

The relationship between the transient circulation and convection over the Northern Hemisphere Tropical Pacific and the ENSO cycle described in this paper can be directly compared to the relationship between the transients and the Madden-Julian oscillation (Matthews and Kiladis 1999). The weak jet or La Niña scenario described here is analogous to the phase of the MJO with enhanced convection over the east Indian Ocean and Indonesia. The retracted Pacific jet and strengthened equatorial westerly duct during this phase of the MJO leads to enhanced equatorward propagation of transient waves and enhanced transient convection over the Northern Hemisphere tropical Pacific. The time-mean OLR signal associated with this change in the transient convection likely feeds back onto the MJO basic state in a similar manner as the time-mean heating anomaly interacts with the interannually varying basic state in this study. However, this complex system of interactions is further compounded in the MJO case, as the timescales between the transient convection and the MJO are not well separated. In particular, in the 1-2 weeks that it takes for an extratropical response to tropical heating to become established, the MJO, with a period near 45 days, will have progressed to another phase.

Acknowledgments. The authors would like to thank Nick Hall, Tercio Ambrizzi, and Jake Badger for help in running the primitive equation model. The comments of Matthew Wheeler, Harry Hendon, and an anonymous reviewer greatly improved the original manuscript. The OLR and NCEP-NCAR reanalysis data were provided through the NOAA Climate Diagnostics Center (http:// www.cdc.noaa.gov). The NINO3.4 SST data were from the NOAA/NCEP Climate Prediction Center. This research was supported by the Pan-American Climate Studies Program, under Project GC95-820, sponsored by NOAA's Office of Global Programs.

\section{APPENDIX}

\section{Statistical Significance}

A resampling technique was used to determine the statistical significance of the SJ minus WJ difference fields in sections 3 and 4. The ZWI was found to be serially uncorrelated (its autocorrelation function was indistinguishable from zero at the $5 \%$ level for all nonzero lags) and was modeled by a synthetic time series of 30 values (corresponding to the 30 winters in Fig. 1) chosen randomly from a Gaussian distribution. Ten thousand such synthetic time series were generated. For each of these "Monte Carlo" simulations, the synthetic time series was processed identically to the ZWI, such that the seven winters with the highest (lowest) values of the synthetic time series were denoted as "SJ" ("WJ") winters. An "SJ minus WJ" difference map was then constructed, corresponding to that particular synthetic time series. The 10000 maps defined the null distribution against which the actual realization of the SJ minus WJ difference map (as determined by the real ZWI) was then tested for statistical significance.

In the case of OLR-based variables, random time series were constructed for the 22 northern winters for which the OLR data were available. As there were only 


\section{$<30$-day OLR variance}

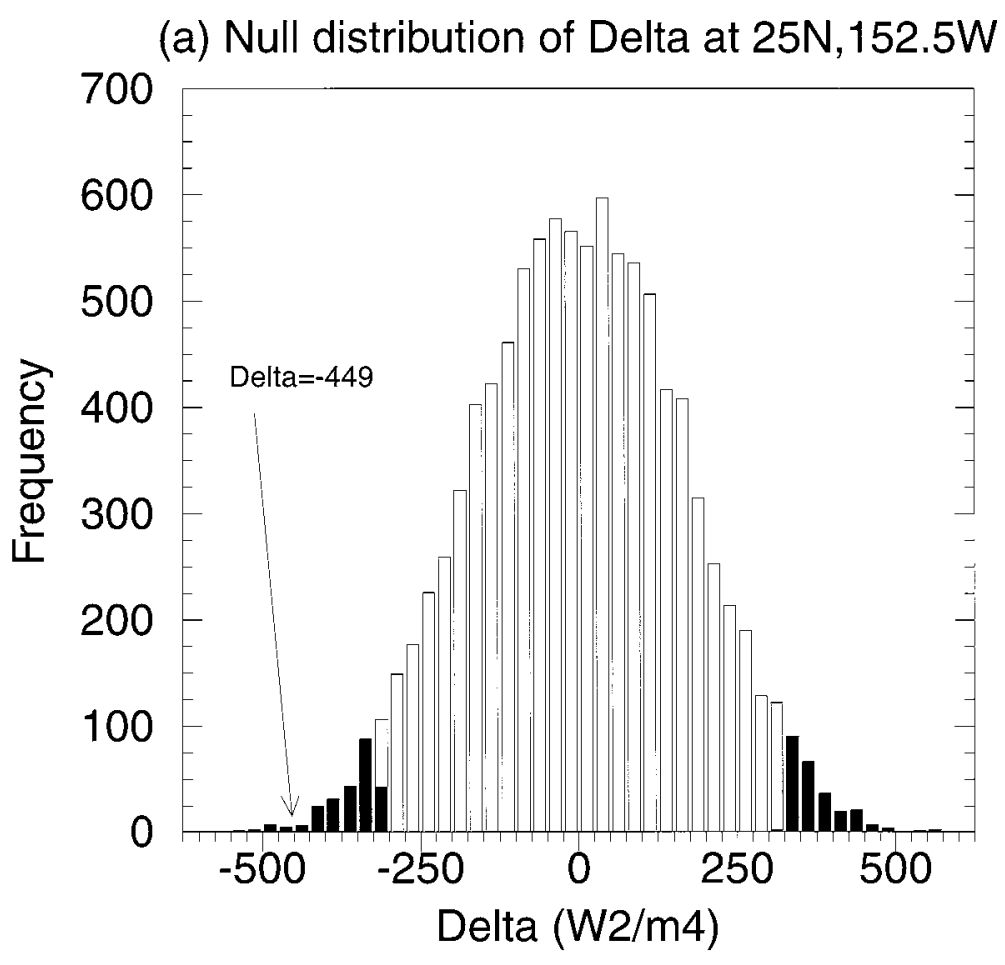

(b) Null distribution of $f$

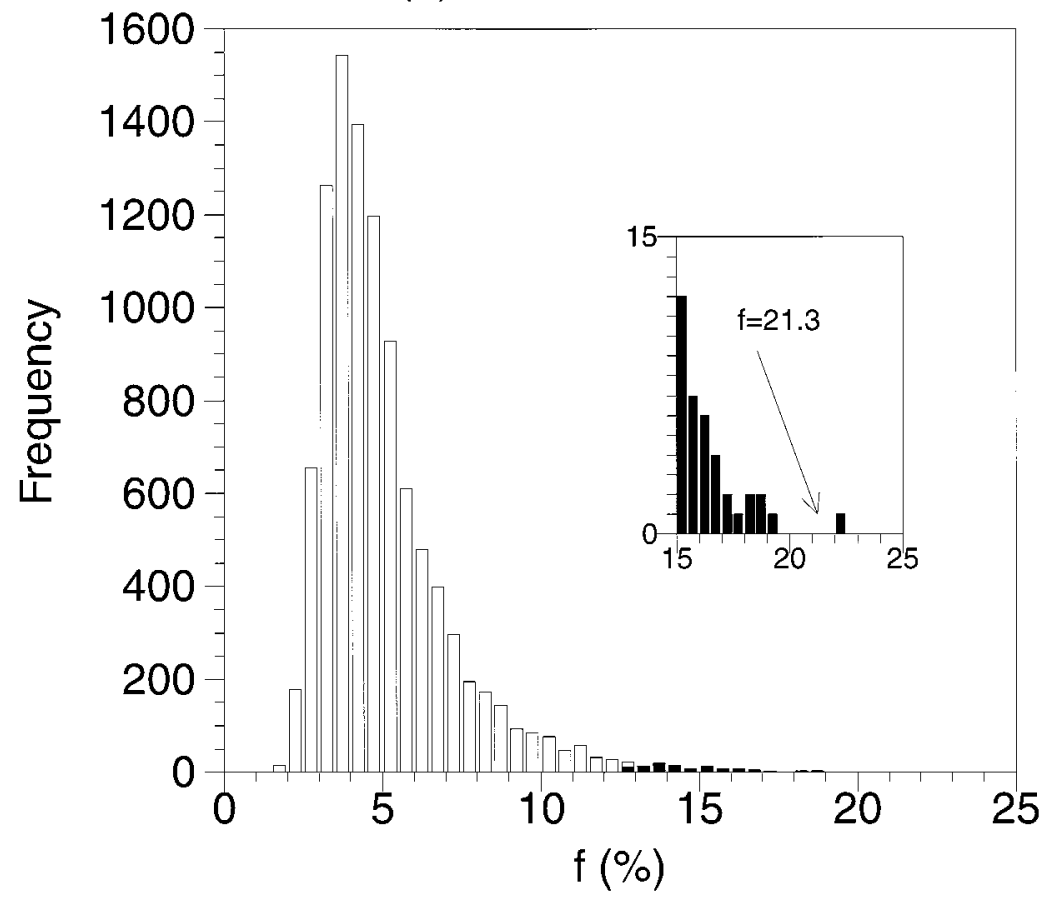

FIG. A1. Statistical significance of the SJ - WJ difference field $(\Delta)$ for OLR variance. (a) Synthetically generated null distribution of $\Delta$ at a selected grid point $\left(25^{\circ} \mathrm{N}, 152.5^{\circ} \mathrm{W}\right)$. The lower and upper 2.5th percentiles are shaded, and the true value of $\Delta$ is indicated. (b) Synthetically generated null distribution of $f$, the fractional area of the globe that is locally statistically significant at the 5\% level. The inset shows the right-hand tail of the distribution in detail. The upper first percentile is shaded, and the true value of $f$ is indicated. 
(a) $200-\mathrm{mb} \mathrm{U}$

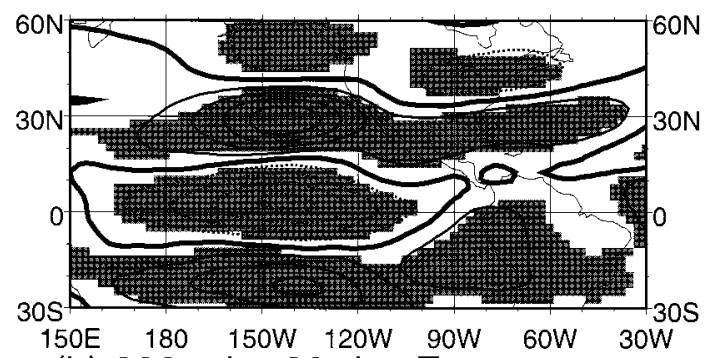

(b) $200-\mathrm{mb}<30$-day E-vector

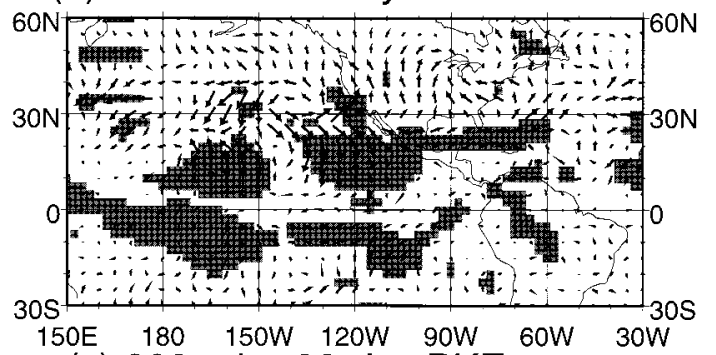

(c) 200-mb <30-day PKE

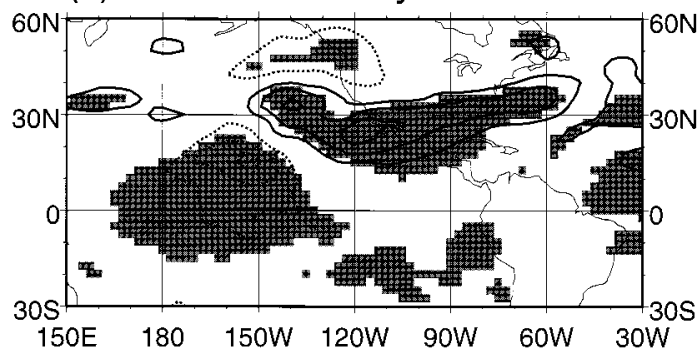

(d) OLR

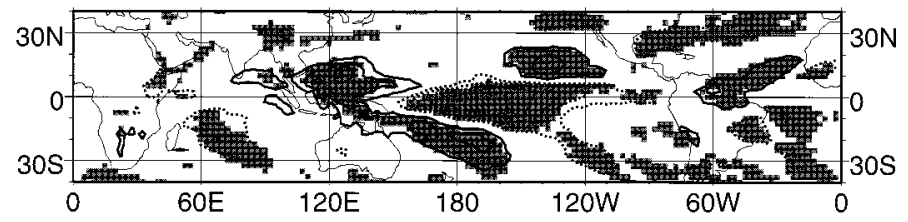

(e) <30-day OLR variance

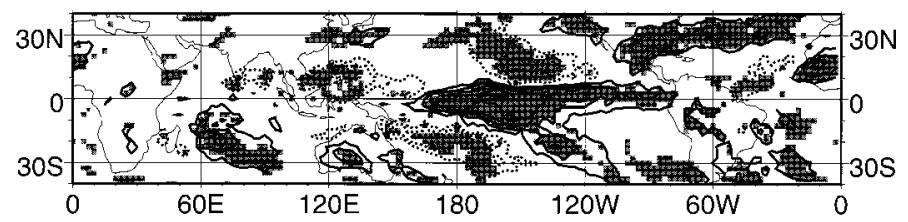

FIG. A2. Statistical significance maps of the SJ-WJ difference fields $(\Delta)$. Contours are the same as those in other diagrams (listed below), showing the actual $\Delta$ fields in more detail. Shading denotes local significance at the $5 \%$ level. (a) The $200-\mathrm{mb}$ zonal wind (see Fig. 2c). (b) The $200-\mathrm{mb}<30$ day E-vectors (see Fig. 4c). (c) The 200-mb $<30$ day PKE (see Fig. 4c). (d) OLR (see Fig. 3c). (e) $<30$ day OLR variance (see Fig. 5c).

five SJ winters and four WJ winters for which OLR data were available (Table 1), the highest five values of the random time series were denoted "SJ" winters and the lowest four values of the random time series were denoted "WJ" winters in the Monte Carlo simulations.

The method of statistical significance testing is now described, using the SJ minus WJ difference field $(\Delta)$ of the $<30$ day OLR variance as an example. First, local statistical significance was tested for. For each grid point, a histogram of the null distribution of $\Delta$ was built up from the 10000 Monte Carlo simulations. Figure A1a shows such a histogram for $<30$ day OLR variance at a selected grid point $\left(25^{\circ} \mathrm{N}, 152.5^{\circ} \mathrm{W}\right)$. The mean of this synthetically generated null distribution is zero, consistent with the null hypothesis $H_{0}: \Delta=0$. The alternative hypothesis is simply $H_{A}: \Delta \neq 0$, so a twotailed test was performed, and if the true value of $\Delta$ lies to the left of the 2.5th percentile or to the right of the 97.5th percentile (shaded in Fig. A1a), it is statistically significant at the $5 \%$ level at that grid point. At the selected grid point $\Delta=-449 \mathrm{~W}^{2} \mathrm{~m}^{-4}$ (see Fig. 5c). This lies well to the left of the 2.5 th percentile $(\Delta=$ $-315 \mathrm{~W}^{2} \mathrm{~m}^{-4}$ ), as indicated in Fig. A1a, and is therefore significant. A map of the local statistical significance of

$\Delta$ for $<30$ day OLR variance is shown in Fig. A2e. The selected grid point at $25^{\circ} \mathrm{N}, 152.5^{\circ} \mathrm{W}$ is seen to be part of a band of locally significant $\Delta$ that lies over the Northern Hemisphere subtropical Pacific.

The map of local statistical significance at each grid point was then tested for global statistical significance (Livezey and Chen 1983) to take account of the finiteness of the sample size and any spatial correlations in the data. The test statistic was $f$, the percentage area of the globe of $\Delta$ that is locally significant at the 5\% level; for the $<30$ day OLR variance $f=21.3 \%$. The null distribution of $f$ was generated from the percentage area of the globe that was locally significant in each of the 10000 Monte Carlo simulations (Fig. A1b). The mean value of this distribution is the expected value of $f=$ $5 \%$. If the data were spatially uncorrelated, the null distribution in Fig. A1b would be a vanishingly narrow spike at $f=5 \%$. However, because of the spatial correlations in the OLR field, the distribution exhibits considerable spread and positive skewness about this mean value.

If $H_{A}: \Delta \neq 0$ was true, there would be some genuinely locally significant regions of the globe in addition to the expected 5\%, and $f$ should be well above 5\%. A 
TABLE A1. Global significance of the 5\% local significance maps of the SJ - WJ difference fields $(\Delta)$ shown in Fig. A2. Here, $f$ is the percentage of global area that is locally significant at the $5 \%$ level, and $f_{99}$ is the $1 \%$ significance level for $f$.

\begin{tabular}{lcr}
\hline \hline & $f$ & \multicolumn{1}{c}{$f_{99}$} \\
\hline $200-\mathrm{mb} u$ & 37.8 & 19.42 \\
$200-\mathrm{mb} E_{x}$ & 8.28 & 8.24 \\
200-mb $E_{y}$ & 9.89 & 8.10 \\
200-mb PKE & 21.85 & 12.64 \\
OLR & 22.17 & 14.11 \\
OLR variance & 21.26 & 12.71 \\
\hline
\end{tabular}

one-tailed test is performed for a "global significance" level of $1 \%$. As the true value of $f=21.3 \%$ lies to the right of the 99th percentile $f_{99}=12.7 \%$ in Fig. A1b, the $5 \%$ local significance map of $\Delta$ for $<30$ day OLR variance is globally significant at the $1 \%$ level. All the $\Delta$ fields in Fig. A2 are globally significant at the $1 \%$ level (Table A1).

The statistical significance of the regression fields in section 5 was assessed using a resampling technique similar to that described above. The correlation coefficient $r$ between the reference time series and the time series of the dependent variable at each grid point was tested under the null hypothesis $H_{0}: r=0$. To account for serial correlations in the data, a first-order autoregressive $[\mathrm{AR}(1)]$ model was fitted to the unfiltered daily mean reference time series of the independent variable. For each of 2000 Monte Carlo simulations, a synthetic time series was generated by the $\mathrm{AR}(1)$ model and passed through the 30-day high-pass filter to give it similar autocorrelation characteristics to the reference time series. The correlation coefficient between the synthetic time series and the dependent variable at each grid point was then calculated, and the null distribution of $r$ was generated from the 2000 synthetic correlation maps. The local and global significance of $r$ were then determined in the same way as for $\Delta$. Most of the regression fields are highly significant (Table A2).

Finally, the statistical significance testing of the skew-

TABLE A2. Global significance of the correlation maps in Figs. 7 10. The percentage of global area that is locally significant at the $5 \%$ level, $f$, is shown in the body of the table, together with the highest significance level that $f$ exceeds ( $f$ was tested at the $50 \%, 25 \%, 10 \%$, $5 \%, 1 \%$, and $0.5 \%$ levels).

\begin{tabular}{crcll}
\hline \hline Figure & Lag & $200-\mathrm{mb} u$ & $200-\mathrm{mb} v$ & OLR \\
\hline $7 \mathrm{a}$ & -2 & $13.2(0.5)$ & $13.9(0.5)$ & \\
$7 \mathrm{~b}$ & 0 & $13.0(0.5)$ & $13.9(0.5)$ & \\
$7 \mathrm{c}$ & +3 & $6.3(25)$ & $10.2(5)$ & \\
$8 \mathrm{a}$ & -2 & $12.4(0.5)$ & $12.6(0.5)$ & \\
$8 \mathrm{~b}$ & 0 & $13.9(0.5)$ & $13.9(0.5)$ & \\
$8 \mathrm{c}$ & +3 & $10.4(1)$ & $10.6(0.5)$ & \\
$9 \mathrm{a}$ & -4 & $9.4(5)$ & $10.2(5)$ & $7.9(0.5)$ \\
$9 \mathrm{~b}$ & -2 & $13.0(0.5)$ & $12.3(0.5)$ & $9.1(0.5)$ \\
$9 \mathrm{c}$ & 0 & $13.0(0.5)$ & $12.0(0.5)$ & $9.0(0.5)$ \\
$9 \mathrm{~d}$ & +2 & $8.1(5)$ & $7.9(10)$ & $8.3(0.5)$ \\
10 & 0 & $9.0(5)$ & $6.8(25)$ & $9.0(0.5)$ \\
\hline
\end{tabular}

ness of the OLR time series in Fig. 6 is described. The null hypothesis was $H_{0}: \gamma=0$, where the sample skewness coefficient

$$
\gamma=\frac{1}{s^{3}(N-1)} \sum_{i=1}^{N}\left(x_{i}-\bar{x}\right)^{3}
$$

$x_{i}$ are the daily mean OLR values for each of the $N \approx$ 90 days during an individual winter, and $\bar{x}$ and $s$ are the sample mean and standard deviation, respectively. An AR(1) model was fitted to the daily mean OLR time series for the five SJ winters and 2000 synthetic time series of length $N=90$ days were constructed from this $\mathrm{AR}(1)$ model and used to generate the null distribution of $\gamma$. The alternative hypothesis was $H_{A}: \gamma<0$; therefore, the observed values of $\gamma$ were compared against the null distribution by a one-tailed test. All five observed values of $\gamma$ for the five SJ winters lay to the left of the 0.5 th percentile, and therefore $H_{0}$ was rejected and $\gamma$ was significantly less than zero at the $0.5 \%$ level. The four WJ winters were also analyzed in an identical manner, and the null hypothesis was rejected in $3 / 4$ cases at the $5 \%$ level.

\section{REFERENCES}

Ambrizzi, T., 1994: Rossby wave propagation on El Niño and La Niña basic flows. Rev. Bras. Meteor., 9, 54-65.

Arkin, P. A., and P. E. Ardanuy, 1989: Estimating climatic-scale precipitation from space: A review. J. Climate, 2, 1229-1238.

Barnston, A. G., and R. E. Livezey, 1987: Classification, seasonality and persistence of low-requency atmospheric circulation patterns. Mon. Wea. Rev., 115, 1083-1126.

Hendon, H. H., 1986: The time-mean flow and variability in a nonlinear model of the atmosphere with tropical diabatic forcing. $J$. Atmos. Sci., 43, 72-88.

Hoerling, M. P., and M. Ting, 1994: Organization of extratropical transients during El Niño. J. Climate, 7, 745-766.

—- A. Kumar, and M. Zhong, 1997: El Niño, La Niña, and the nonlinearity of their teleconnections. J. Climate, 10, 1769-1786.

Hosaka, M., M. Ishiwatari, S. Takehiro, K. Nakajima, and Y. Hayashi, 1998: Tropical precipitation patterns in response to a local warm SST area placed at the equator of an aqua planet. J. Meteor. Soc. Japan, 76, 289-305.

Hoskins, B. J., and A. J. Simmons, 1975: A multi-layer spectral model and the semi-implicit method. Quart. J. Roy. Meteor. Soc., 101, $637-655$.

— turbations to a baroclinic atmosphere. Quart. J. Roy. Meteor. Soc., 117, 299-318.

— , and T. Ambrizzi, 1993: Rossby wave propagation on a realistic longitudinally varying flow. J. Atmos. Sci., 50, 1661-1671.

— I. N. James, and G. H. White, 1983: The shape, propagation and mean-flow interaction of large-scale weather systems. $J$. Atmos. Sci., 40, 1595-1612.

Iskenderian, H., 1995: A 10-year climatology of Northern Hemisphere tropical cloud plumes and their composite flow patterns. J. Climate, 8, 1630-1637.

Jin, F.-F., and B. J. Hoskins, 1995: The direct response to tropical heating in a baroclinic atmosphere. J. Atmos. Sci., 52, 307-319.

Kalnay, E., and Coauthors, 1996: The NCEP/NCAR 40-Year Reanalysis Project. Bull. Amer. Meteor. Soc., 77, 437-471.

Kiladis, G. N., 1998: An observational study of Rossby waves linked to convection over the eastern tropical Pacific. J. Atmos. Sci., 55, 321-339.

_, and H. van Loon, 1988: The Southern Oscillation. Part VII: 
Meteorological anomalies over the Indian and Pacific sectors associated with the extremes of the oscillation. Mon. Wea. Rev., 116, 120-136.

- , and H. F. Diaz, 1989: Global climatic anomalies associated with extremes in the Southern Oscillation. J. Climate, 2, 10691090.

_ , and K. M. Weickmann, 1992a: Circulation anomalies associated with tropical convection during northern winter. Mon. Wea. Rev., 120, 1900-1923

$\longrightarrow$, and $-1992 \mathrm{~b}$ : Extratropical forcing of tropical Pacific convection during northern winter. Mon. Wea. Rev., 120, 19241938.

— scale circulations associated with submonthly tropical convection. Mon. Wea. Rev., 125, 1997-2013.

_ , and K. C. Mo, 1998: Interannual and intraseasonal variability in the Southern Hemisphere. Meteorology of the Southern Hemisphere, Meteor. Monogr., No. 49, Amer. Meteor. Soc., 307-336.

Lau, K.-M., and P. H. Chan, 1988: Intraseasonal and interannual variations of tropical convection: A possible link between the 40-50 day oscillation and ENSO? J. Atmos. Sci., 45, 506-521.

Liebmann, B., and C. A. Smith, 1996: Description of a complete (interpolated) OLR dataset. Bull. Amer. Meteor. Soc., 77, 12751277.

Livezey, R. E., and W. Y. Chen, 1983: Statistical field significance and its determination by Monte Carlo techniques. Mon. Wea. Rev., 111, 46-59.

Matthews, A. J., and G. N. Kiladis, 1999: The tropical-extratropical interaction between high-frequency transients and the MaddenJulian oscillation. Mon. Wea. Rev., 127, 661-677.

_ B. J. Hoskins, J. M. Slingo, and M. Blackburn, 1996: Devel- opment of convection along the SPCZ within a Madden-Julian oscillation. Quart J. Roy. Meteor. Soc., 122, 669-688.

McGuirk, J. P., A. H. Thompson, and N. R. Smith, 1987: Moisture bursts over the tropical Pacific Ocean. Mon. Wea. Rev., 115, 787-798.

—, - - and J. R. Schaefer, 1988: An eastern Pacific tropical plume. Mon. Wea. Rev., 116, 2505-2521.

Rasmusson, E. M., 1985: El Niño and variations in climate. Amer. Sci., 73, 168-177.

Reynolds, C., and R. Gelaro, 1997: The effect of model bias on the equatorward propagation of extratropical waves. Mon. Wea. Rev., 125, 3249-3265.

Slingo, J. M., 1998: Extratropical forcing of tropical convection in a northern winter simulation with the UGAMP GCM. Quart $J$. Roy. Meteor. Soc., 124, 27-52.

Tomas, R. A., and P. J. Webster, 1994: Horizontal and vertical structure of cross-equatorial wave propagation. J. Atmos. Sci., 51, $1417-1430$.

Vincent, D. G., A. Fink, J. M. Schrage, and P. Speth, 1998: Highand low-frequency intraseasonal variance of OLR on annual and ENSO timescales. J. Climate, 11, 968-986.

Webster, P. J., and J. R. Holton, 1982: Cross-equatorial response to middle-latitude forcing with a latitudinally and zonally nonuniform basic state. J. Atmos. Sci., 39, 722-733.

Yanai, M., and T. Tomita, 1998: Seasonal and interannual variability of atmospheric heat sources and moisture sinks as determined from NCEP-NCAR reanalysis. J. Climate, 11, 463-482.

_- S. Esbenson, and J.-H. Chu, 1973: Determination of bulk properties of tropical cloud clusters from large-scale heat and moisture budgets. J. Atmos. Sci., 30, 611-627.

Yang, G.-Y., and B. J. Hoskins, 1996: Propagation of Rossby waves of nonzero frequency. J. Atmos. Sci., 53, 2365-2378. 